Hélio Ponciano Trevenzol

\title{
Operação de Serra Dória no tratamento do megaesôfago operado com recidiva dos sintomas
}

Dissertação apresentada à

Faculdade de Medicina da

Universidade de São Paulo para obtenção do titulo de Mestre em

Ciências

Área de Concentração: Cirurgia do Aparelho Digestivo

Orientador: Prof. Dr. Ivan Cecconello

SÃO PAULO

2003 


\section{FICHA CATALOGRÁFICA}

Preparada pela Biblioteca da

Faculdade de Medicina da Universidade de São Paulo

Creprodução autoriza pelo autor

Trevenzol, Hélio Ponciano

Operação de Serra Dória no tratamento do megaesôfago operado com recidiva dos sintomas / Hélio Ponciano Trevenzol. -- São Paulo, 2003.

Dissertação (mestrado) -- Faculdade de Medicina da Universidade de São Paulo. Departamento de Gastroenterologia.

Área de concentração: Cirurgia do Aparelho Digestivo.

Orientador: Ivan Cecconello.

Descritores: 1.ACALASIA ESOFÁGICA/cirurgia 2.RECIDIVA

3. ESOFAGOPLASTIA/métodos 4.ESTUDOS RETROSPECTIVOS

5. SEGUIMENTOS

USP/FM/SBD-392/03 
Esta Dissertação foi desenvolvida dentro do Mestrado Interinstitucional entre as Faculdades de Medicina da Universidade Federal de Goiás e Medicina da Universidade de São Paulo.

Unidade promotora - FMUSP Coordenadores:

Prof. Dr.Bruno Zilberstein Prof. Dr.Joaquim Gama-Rodrigues

Unidade receptora - FMUFG Coordenador:

Prof. Dr. Heitor Rosa 
À meus avós Geraldo e Emília (In Memoriam) a minha eterna gratidão pelos ensinamentos.

A Manoel e Dinebra, meus pais, pela orientação de meus passos iniciais, sem os quais, nada disto seria possível. 
A llza, minha esposa, pelo amor, companheirismo e cumplicidade.

A minhas filhas, Juliana, Andréia e Fernanda pelo estímulo constante, todo o meu respeito. 


\section{AGRADECIMENTOS}

Gostaria de agradecer a todos que, de algum modo, contribuíram para que esse trabalho e o aprendizado a ele vinculado fossem possíveis, mesmo que não tenham sido aqui citados, e em especial :

Ao Professor Ivan Cecconello, orientador que aprendi a admirar e respeitar, pois nos momentos de maiores dificuldades sempre tinha uma palavra de consolo e estímulo.

Ao Professor Bruno Zilberstein, com a sua tenacidade e persistência, rompendo todas as barreiras, propiciou a realização deste mestrado.

Ao Professor Joaquim Gama-Rodrigues, por permitir e viabilizar a realização desta interação entre Faculdade de Medicina da UFG e Faculdade de Medicina da USP.

Ao Professor Manoel Maria Pereira dos Santos, por abrir as portas da Faculdade de Medicina da UFG e ter me mostrado o caminho do ensino. Obrigado pela oportunidade de crescimento.

À Professora Eleuse Machado de Britto Guimarães, grande incentivadora, presente em todos os momentos de dificuldades.

Ao Dr Leósarte Alves, pelo companheirismo nos momentos de incerteza da implantação deste mestrado interinstitucional . 
Ao Professor Gercino Monteiro Filho, pelo auxílio com a análise estatística.

À Bibliotecária Maria Raquel G. Silva, pelo cotejo das referência bibliográficas.

Às secretarias da pós graduação, Benedita, Deusa, Patricia e Andréa que estavam sempre dispostas a nos auxiliar no esclarecimento e preenchimento de documentação para cumprir os prazos regulamentares. 


\section{SUMÁRIO}

Lista de abreviaturas e símbolos

Lista de tabelas

Lista de figuras

Resumo

Summary

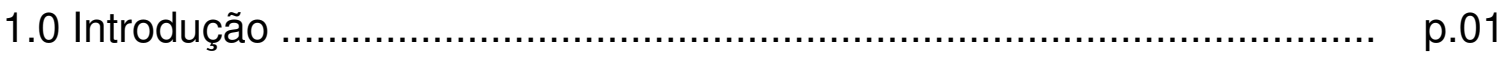

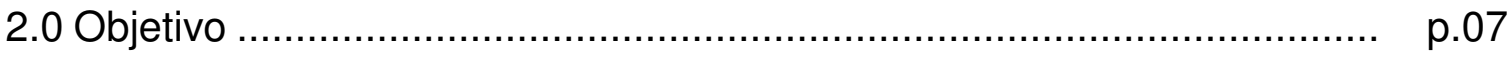

3.0 Casuística e Método .......................................................... p.09

3.1 Casuística ....................................................................... p.10

3.2 Método …...................................................................... p.11

3.2.1 Avaliação clínica ......................................................... p.11

3.2.2 Avaliação radiológica .............................................. p.11

3.2.3 Avaliação endoscópica .................................................. p.13

3.2.4 Diagnóstico de causa de recidiva dos sintomas após

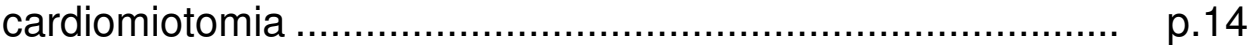

3.2.5 Técnica cirúrgica ..................................................... p.15

3.2.5.1 Preparo do paciente .................................... p.15

3.2.5.2 Técnica operatória …........................................ p.16

3.2.5.3 Cuidados pós-operatórios ..................................... p.26

3.2.6 Complicações intra e pós-operatória ….............................. p.26

3.2.7 Seguimento pós-operatório …........................................ p.26 
3.2.8 Análise estatística ….................................................. p.27

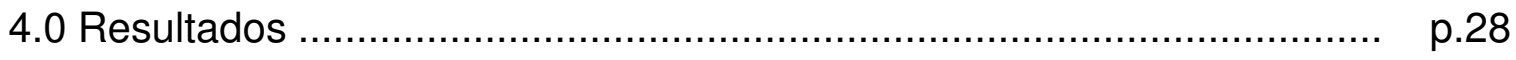

4.1 Diagnóstico de causas de recidiva ……………........................ p.29

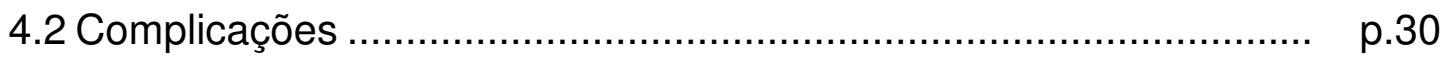

4.3 Avaliação clínica ………………........................................ p.31

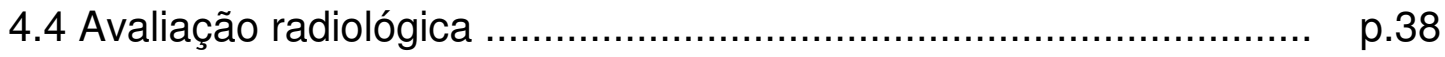

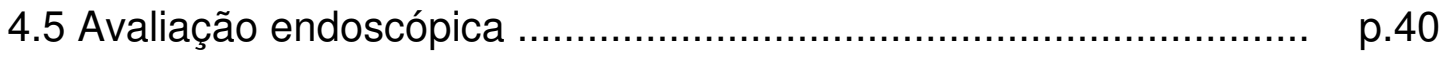

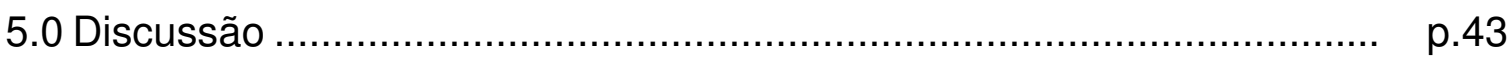

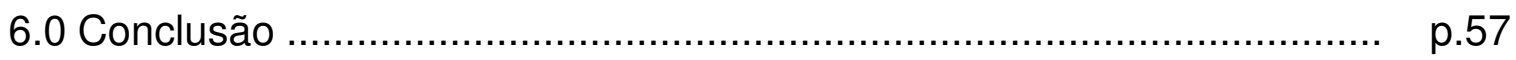

7.0 Referências Bibliográficas ………….......................................... p.59

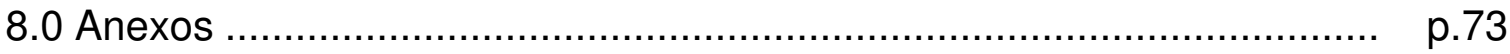

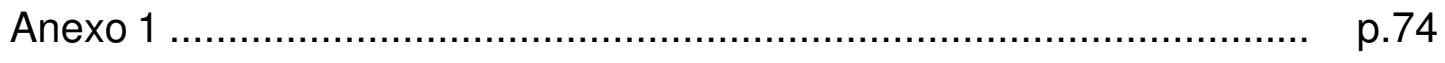

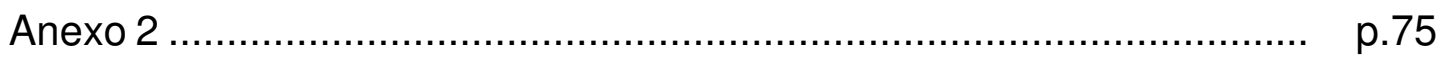

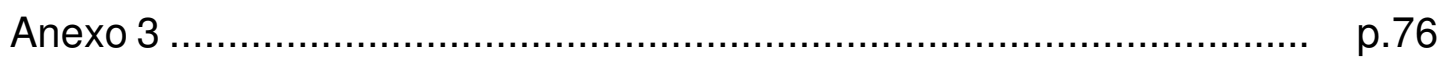

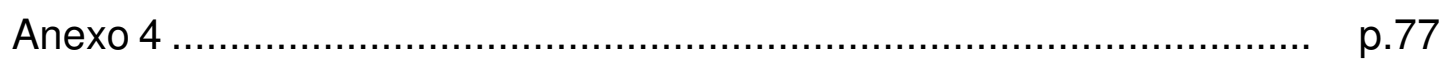




\section{LISTA DE ABREVIATURAS E SÍMBOLOS}

$\begin{array}{cc}\text { cm } & \text { centímetro } \\ \text { EIE } & \text { esfíncter inferior do esôfago } \\ \text { ed. } & \text { edição } \\ \text { et al. } & \text { e outros } \\ \text { min } & \text { minuto } \\ \text { mm } & \text { milímetro } \\ \mathrm{n}^{\circ} & \text { número } \\ \mathrm{p} . & \text { página } \\ \mathrm{p} & \text { nível de significância } \\ \mathrm{Rev.} & \text { revista } \\ \mathrm{RGE} & \text { refluxo gastroesofágico } \\ \text { TEG } & \text { transição esofagogástrica } \\ \% & \text { porcentagem }\end{array}$




\section{LISTA DE TABELAS}

Tabela 1 Diagnóstico da causa de recidiva dos sintomas após cardiomiotomia

Tabela 2 Causa de recidiva dos sintomas após cardiomiotomia p.29

Tabela 3 Complicações intra e pós-operatória da operação de Serra Dória para tratamento do megaesôfago já operado

Tabela 4 Avaliação da disfagia no pré e pós-operatório imediato de pacientes com megaesôfago submetido à operação de SerraDória - 20 pacientes

Tabela 5 Avaliação da disfagia no pré e pós-operatório tardio operação de Serra Dória -17 pacientes

Tabela 6 Avaliação da regurgitação no pré e pós operatório imediato operação de Serra Dória - 20 pacientes

Tabela 7 Avaliação da regurgitação no pré e pós-operatório tardio operação de Serra Dória -17 pacientes

Tabela 8 Avaliação da pirose no pré e pós-operatório imediato operação de Serra Dória -20 pacientes

Tabela 9 Avaliação da pirose no pré e pós-operatório tardio - operação de Serra Dória -17 pacientes

Tabela 10 Variação do peso entre o pré e pós-operatório tardio operação de Serra Dória -17 pacientes 
Tabela 11 Avaliação radiológica no pré e pós-operatório tardio operação de Serra Dória -13 pacientes

Tabela 12 Avaliação endoscópica no pré e pós-operatório tardio operação de Serra Dória -17 pacientes 


\section{LISTA DE FIGURAS}

Figura 1 Classificação radiológica do megaesôfago em quatro grupos, baseados no diâmetro do esôfago e alterações motoras do órgão

Figura 2 Locais para realização da laparotomia. a) preferencialmente mediana e, se necessário, com prolongamento infraumbilical. B) sobre cicatriz de laparotomia já existente

Figura 3 As imagens representam aderências freqüentemente existentes nas reoperações para megaesôfago, entre o estômago e estruturas adjacentes, principalmente fígado

Figura 4 Dissecção do esôfago distal com passagem de dreno de Penrose para tração

Figura 5 Plicatura do fundo gástrico à face esquerda do esôfago distal p.21

Figura 6 Anastomose esofagogástrica látero-lateral: a) realização de sutura posterior com pontos separados de algodão; b) esquema da sutura do plano posterior; c) anastomose esofagogástrica realizada com grampeador linear cortante de $75 \mathrm{~mm}$ 
Figura 8 Ressecção gástrica com anastomose gastrojejunal: a) esquema mostrando o estômago a ser ressecado; b) estômago e jejuno aprisionado com pinça de Abbadie para realização de anastomose; c) anastomose gastrojejunal término-lateral, demonstrando as suturas seromuscular e muco-mucosa posterior

Figura 9 Anastomose jejuno-jejunal término-lateral ( Y-de-Roux) $40 \mathrm{~cm}$ abaixo da gastrojejunal

Figura 10 Esquema do aspecto final da operação com visualização de todas as anastomoses

Figura 11 Representação gráfica da avaliação da disfagia no pré e pósoperatório imediato - operação de Serra Dória - 20 pacientes

Figura 12 Representação gráfica da avaliação da disfagia no pré e pósoperatório tardio - operação de Serra Dória - 17 pacientes

Figura 13 Representação gráfica da avaliação radiológica no pré e pósoperatório tardio - operação de Serra Dória -13 pacientes

Figura 14 Avaliação endoscópica no pré e pós-operatório tardio operação de Serra Dória -17 pacientes 


\section{RESUMO}


TREVENZOL, H. P. Operação de Serra Doria no tratamento do megaesôfago operado com recidiva dos sintomas. São Paulo, 2003. 77p. Dissertação (Mestrado) - Faculdade de Medicina da Universidade de São Paulo.

Nas operações de cardiomiotomia para tratamento do megaesôfago ocorre recidiva dos sintomas em até $15 \%$ dos pacientes, sendo que alguns necessitam reoperação. Foram estudados de forma retrospectiva, 20 pacientes com megaesôfago previamente tratados por cardiomiotomia e submetidos a reoperação, por cardioplastia com gastrectomia parcial em Y-de-Roux, conforme técnica proposta por Serra Dória et al (1970). A causa de recidiva dos sintomas foi esofagite de refluxo em nove $(45,0 \%)$, miotomia incompleta em um $(5,0 \%)$, cicatrização da miotomia em cinco $(25,0 \%)$ e presença de megaesôfago avançado em cinco (25,0\%). Foram analisadas as complicações intra e pósoperatórias. Os pacientes foram avaliados sob o ponto de vista clínico (disfagia, regurgitação, pirose e variação de peso), radiológico e endoscópico, no pré e no pós-operatório imediato e tardio. Cinco $(25,0 \%)$ doentes apresentaram complicações no pós-operatório imediato. Não houve mortalidade. Todos os doentes melhoraram da disfagia, com quase total desaparecimento da regurgitação e pirose. Houve manutenção ou aumento de peso em $64,7 \%$ dos pacientes. O estudo radiológico mostrou diminuição do calibre do esôfago em $53,0 \%$ e manutenção nos demais. Não houve aumento do calibre em nenhum dos pacientes. No exame endoscópico realizado no pós-operatório tardio em 17 
pacientes, observou-se que seis entre nove que apresentavam esofagite de refluxo, melhoraram; dois entre oito, que apresentavam esôfago normal no préoperatório, desenvolveram esofagite. Concluiu-se que a operação de Serra Dória para tratamento do megaesôfago, operado por cardiomiotomia com recidiva dos sintomas apresentou baixa morbidade e ausência de mortalidade. Permitiu expressivo alívio dos sintomas e diminuição do calibre do esôfago em vários doentes. Possibilitou também melhora da esofagite de refluxo, havendo, entretanto, a possibilidade de sua manutenção, bem como do seu aparecimento em doentes que não a apresentavam. 
SUMMARY 
TREVENZOL, H. P. The Serra Dória procedure for reoperation of megaesophagus with recurrence of symptoms. São Paulo,2003. 77 p. Tesis (Master 's Degree) - University of São Paulo Faculty of Medicine.

After cardiomyotomy for the treatment of megaesophagus, recurrence of symptoms occur in up to $15 \%$ of the patients, but only some require a reoperation. Twenty patients with megaesophagus were retrospectively studied. They were previously treated by cardiomyotomy, and underwent to reoperation through cardioplasty with Roux-en-Y partial gastrectomy, according to the technique proposed by Serra Dória et al (1970). The etiology of symptoms recurrence was reflux esophagitis in nine (45.0\%) patients, incomplete myotomy in one $(5.0 \%)$, healing of the myotomy in five $(25.0 \%)$ and end staging megaesophagus in five (25.0\%). Intra and postoperative complications were analyzed. The patients were studied by clinical (dysphagia, regurgitation, heartburn and weight gain), radiological and endoscopic evaluation, in the preand postoperative period. Five (25.0\%) patients had complications in the immediate postoperative period. No deaths were observed. Dysphagia improved in all the patients. Regurgitation and heartburn almost disappeared in the whole group. Weight was maintained or increased in $64,7 \%$ of the patients. Radiological studies showed a decrease in the caliber of the esophagus in $53.0 \%$, while the remaining patients maintained the pre-operative diameter. Endoscopy, performed during the late postoperative period in 17 patients, showed that six among the nine with reflux esophagitis improved; two among the eight with a normal esophagus 
during the preoperative period, developed esophagitis. It was concluded that the Serra Dória procedure for the treatment of megaesophagus in patients who had already undergone a cardiomyotomy and whose symptoms recurred, presented a low morbidity and no mortality. It afforded a significant relief of symptoms with a decrease of the caliber of the esophagus in several patients. The patients also improved with regards to reflux esophagitis. In some cases reflux was still present after surgery. Others with normal esophagus in the pre operative period developed esophagitis. 
INTRODUÇÃO 


\subsection{Introdução}

A Doença de Chagas ainda tem alta prevalência em várias regiões do Brasil (WANDERLEY, 1994; LUQUETTI, 1996). Uma de suas manifestações, o megaesôfago, necessita freqüentemente de tratamento cirúrgico.

A cardiomiotomia com fundoplicatura parcial por via abdominal é o tratamento cirúrgico mais aceito desde que não haja desvio do eixo longitudinal do esôfago ( PINOTTI et al., 1974 ).

As cardiomiotomias sofreram modificações desde a proposição de HELLER em 1913( apud ELLENBOGEM, 1979) que a realizava na região anterior e posterior do esôfago. GROENVELDT (1918) ( apud ELLENBOGEM, 1979) a simplificou, passando a realizá-la somente na parede anterior. Esta modificação foi também preconizada por ZAAIJER (1923) ( apud ELLENBOGEM, 1979). As miotomias provocam alteração do esfíncter inferior do esôfago e do mecanismo de contenção do refluxo gastroesofágico, podendo apresentar como conseqüência, esofagite de refluxo. Com o objetivo de prevenir esofagite pósoperatória, alguns autores associaram à miotomia, fundoplicatura parcial anterior, cobrindo com o fundo gástrico a área de mucosa esofágica exposta ( DOR et al., 1962; JECKLER e LOTKA, 1967). Esta modificação técnica não se mostrou suficiente para conter o refluxo.

PINOTTI et al. (1974) com o objetivo de prevenir esta complicação e de evitar a aproximação das bordas da miotomia, propuseram retirada de fita muscular na transição esofagogástrica ( TEG) associada a esofagogastrofundoplicatura envolvendo dois terços da circunferência esofágica. 
A extensão da secção longitudinal da musculatura era de $6 \mathrm{~cm}$ no esôfago distal e $3 \mathrm{~cm}$ no estômago, o que certamente incluía o esfíncter inferior do esôfago ( EIE). Em estudo bem elaborado ELLENBOGEN (1979) mostrou ser este um procedimento eficaz. DEL GENIO et al. ( 1995) mostraram que a fundoplicatura com envolvimento total do esôfago são eficientes na contenção do refluxo, mas apresentam o inconveniente de manter a disfagia por compressão ao nível da TEG.

Quando há recidiva dos sintomas após operação para megaesôfago, o tratamento é também muitas vezes cirúrgico.

As principais causas de recidiva dos sintomas no megaesôfago, após cardiomiotomia em qualquer das técnicas empregadas são : refluxo gastroesofágico com esofagite , miotomia incompleta, fibrose ao nível da secção longitudinal da musculatura da TEG, má indicação da técnica em doentes com megaesôfago avançado e, eventualmente, migração do fundo gástrico para o tórax ( PINOTTI e FELIX 1999).

FÉLIX et al. ( 1989 ) em estudo de 74 doentes com recidiva dos sintomas após cardiomiotomia mostraram uma incidência de esofagite de refluxo pós-miotomia em 28,4\% ,cicatrização da miotomia em 14,8\%, miotomia incompleta em $23 \%$, e aplicação de técnica de forma inadequada por se tratar de pacientes com dolicomegaesôfago, em 21,6\% .

As reoperações geralmente apresentam resultados piores do que os observados no procedimento inicial (ELLIS Jr. e GIBB, 1986; DEL GENIO et al., 1995; SERRA et al., 1996); em certos pacientes é necessária a ressecção esofágica, com suas complicações inerentes . 
O tratamento nestas situações varia conforme a etiologia. Assim, para os doentes com cardiomiotomia incompleta ou cicatrização com fibrose, desde que não haja lesão da parede esofágica durante a dissecção, tem sido a de realização de nova miotomia complementada com fundoplicatura parcial (PINOTTI et al., 1979; SERRA et al., 1996, 1998) .

SERRA et al., (1998) estudaram 12 pacientes com recidiva dos sintomas após miotomia incompleta. A realização de nova miotomia trouxe alívio da disfagia em todos os doentes. Entretanto, pelo maior comprometimento do EIE após a segunda miotomia, observaram a presença de esofagite de refluxo em $40 \%$ dos pacientes.

Nos casos com esofagite de refluxo importante ou com dolicomegaesôfago a indicação tem sido de esofagectomia sem toracotomia com substituição do esôfago pelo estômago (gastroplastia cervical) (PINOTTI, 1977). Antigamente esta operação era realizada por toracotomia com substituição do esôfago pelo estômago ( FERREIRA SANTOS, 1963), ou cólon ( RASSI, 1973). Quando há esofagite sem dilatação pode-se ainda optar pela ressecção do esôfago distal com interposição de alça jejunal pela técnica de MERENDINO e DILLARD （1955) ou do cólon ( RASSI, 1973).

A realização em um só tempo, de esofagectomia sem toracotomia por transsecção mediana do diafragma ( PINOTTI, 1977), permitiu que o procedimento fosse realizado sob visão direta em quase todo o mediastino, fato importante quando se trata de reoperação. A gastroplastia pelo leito do esôfago, realizada no mesmo tempo cirúrgico, melhorou os resultados em relação às operações por toracotomia. Porém, algumas complicações principalmente 
pulmonares, como derrame pleural e broncopneumonia, além de fístula cervical, se mantiveram. Em 162 doentes com megaesôfago operados por esta técnica PINOTTI e MARIANO DA ROCHA (1999) observaram também, cinco óbitos $(3,1 \%)$. Em dois destes, houve hemorragia no mediastino, ocorrendo esta em doentes que já haviam sido operados previamente, observando-se intensa fibrose neste local.

Nas esofagectomias para o megaesôfago, o cólon também foi utilizado como substituto do esôfago, tanto nas formas avançadas como nas recidivas após tratamento cirúrgico. RASSI (1973) observou fístula na anastomose esofagocólica em $54 \%$ dos pacientes e óbito em $4,5 \%$.

HOLTE e LARGE (1961) propuseram tratar a esofagite de refluxo intensa, decorrente de cardioplastia tipo GRÖNDHAL para tratamento da acalásia, por gastrectomia parcial em Y-de-Roux e em caso de estenose esofágica realizavam também abertura ou ressecção desta área comprometida . SERRA DÓRIA et al. (1970) insatisfeitos na época, com os resultados das operações empregadas para tratamento cirúrgico do megaesôfago, utilizaram os mesmos princípios empregados por estes autores. Assim, propuseram para o tratamento inicial do megaesôfago, a associação de ampla anastomose laterolateral entre o esôfago e o fundo gástrico (cardioplastia tipo GRÖNDHAL, 1916 apud CHRISTMANN-OTTOLENGHI, 1975) para facilitar o esvaziamento esofágico, com gastrectomia parcial em Y-de-Roux, a fim de evitar o refluxo biliar. Em 130 pacientes tratados por esta técnica obteve bons resultados em termos de alívio da disfagia. 
Devido baixa morbidade e mortalidade observada no Hospital das Clínicas da Universidade Federal de Goiás com essa técnica, que obedece o principio de melhorar a disfagia e evitar o refluxo, além da facilidade de sua realização, passou-se também a indicá-la para doentes com recidiva dos sintomas após cardiomiotomia, evitando-se assim operações mais complexas . 
OBJETIVO 


\subsection{OBJETIVO}

O objetivo deste trabalho é avaliar os resultados da operação de Serra Dória no tratamento do megaesôfago previamente operado por cardiomiotomia, em que houve recidiva dos sintomas. 
CASUÍSTICA E MÉTODO 


\subsection{CASUÍSTICA}

O estudo obedeceu ao protocolo aprovado no comitê de ética em pesquisa humana e animal do Hospital das Clínicas da Universidade Federal de Goiás e da Comissão de Ética para Análise de Projeto de Pesquisa (CAPPesq) do Hospital das Clínicas da Universidade de São Paulo.

Este estudo é retrospectivo sendo baseado nos dados obtidos nos prontuários de 20 pacientes com megaesôfago chagásico submetidos previamente a cardiomiotomia com ou sem fundoplicatura, que apresentaram recidiva dos sintomas. Todos foram reoperados pela técnica de SERRA DÓRIA nos anos de 1989 a 2001, no Hospital das Clínicas da Faculdade de Medicina da Universidade Federal de Goiás.

Foram excluídos pacientes que apresentavam neoplasia do esôfago associado ao megaesôfago.

A idade dos pacientes variou de 18 a 70 anos (média $=49,6$ anos). Quinze (75\%) eram do sexo masculino e cinco (25\%), do feminino. 


\subsection{MÉTODO}

\subsection{1 - Avaliação clínica}

Os pacientes foram avaliados quanto à presença de sintomas característicos de megaesôfago, quais sejam: disfagia, regurgitação e pirose.

A disfagia foi classificada, de acordo com a dificuldade de ingestão de alimentos, em:

$\begin{array}{ll}\text { leve } & \text { - para alimentos sólidos, } \\ \text { moderada } & \text { - para os pastosos, } \\ \text { intenso } & \text { - para os líquidos. }\end{array}$

A regurgitação e pirose foram assinaladas quanto à sua presença ou ausência.

Foi ainda anotado, o peso dos pacientes.

\subsection{2 - Avaliação radiológica}

Os pacientes foram submetidos a estudo radiológico do esôfago estômago e duodeno. De acordo com os achados radiológicos, os pacientes foram classificados em quatro grupos, conforme classificação de REZENDE et al.( 1960), a saber (figura 1) : 
grupo I - diâmetro do esôfago próximo ao normal com discreta dificuldade de esvaziamento e pequena retenção da substância de contraste;

grupo II - esôfago com moderada dilatação, hipotonia do esôfago inferior com retardo do esvaziamento, presença de ondas terciárias e moderada retenção da substância de contraste;

grupo III- esôfago muito dilatado, hipotonia do esôfago inferior, grande retenção do contraste, esôfago terminal afilado na cárdia, mantendo a posição vertical;

grupo IV- esôfago muito dilatado, com eixo desviado para a direita sobre o diafragma (dolicomega ), retenção por longo tempo do contraste, restos alimentares de difícil limpeza antes da realização do exame, afilamento na região da cárdia, com difícil passagem da substância de contraste para o estômago. 


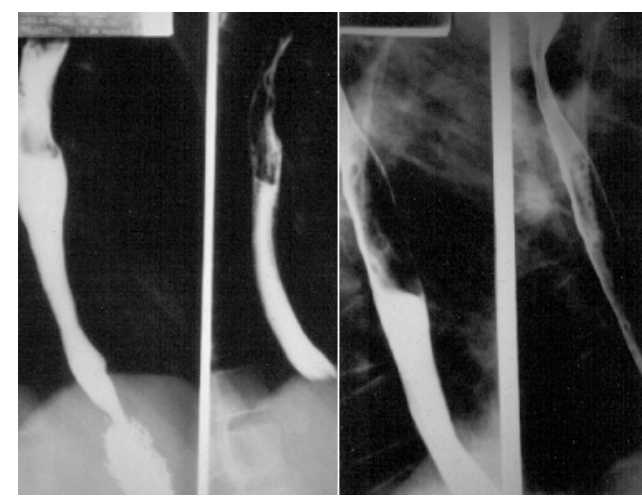

Grupo I

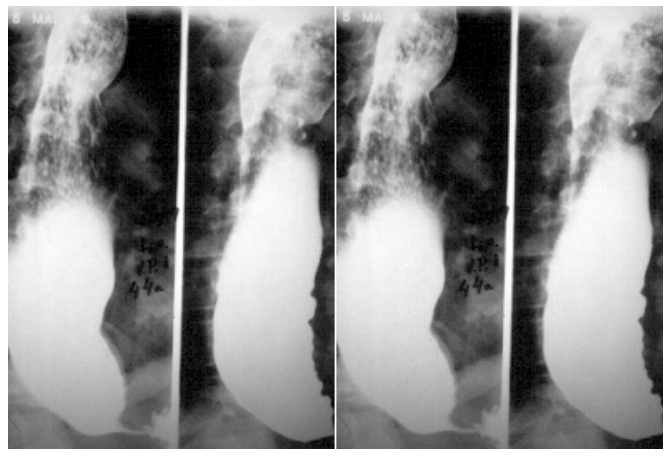

Grupo III

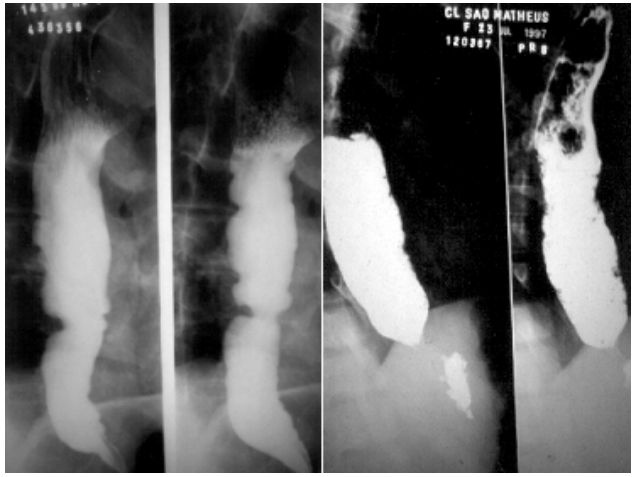

Grupo II

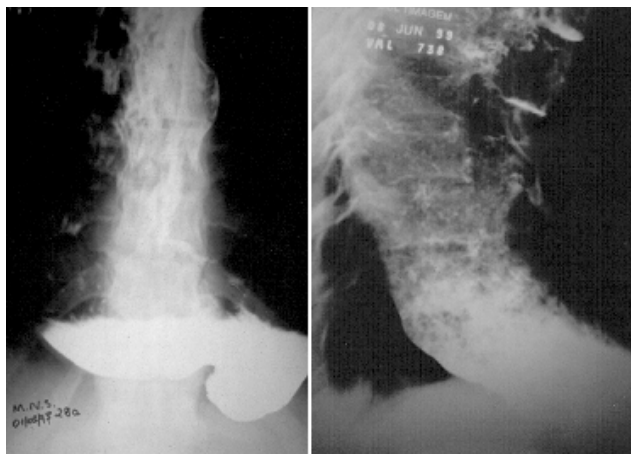

Grupo IV

Figura 1 - Classificação radiológica do megaesôfago em quatro grupos , baseado no diâmetro do esôfago e alterações motoras do órgão (REZENDE et al., 1960 )

\subsection{3 - Avaliação endoscópica}

Todos os pacientes foram submetidos a estudo endoscópico do esôfago. O exame foi realizado com anestesia tópica do orofaringe com lidocaína e sedação suave, empregando-se midazolan via oral. Empregou-se endoscópio Olimpus modelo JF-E e vídeo Pentax, modelo EPM - 300 . 
Foi particularmente avaliado o aspecto da mucosa esofágica, quanto à ausência ou presença de esofagite de refluxo. Consideram-se para esse diagnóstico, a presença de erosões e hiperemia.

\subsection{4 - Diagnóstico da causa de recidiva dos sintomas após}

\section{cardiomiotomia}

As causas de recidiva foram classificadas em : miotomia incompleta, cicatrização na área da miotomia, RGE com esofagite e megaesôfago classificado como grupo IV, em que a miotomia, pela dilatação e alongamento do esôfago, não propiciou melhora da disfagia.

Para o diagnóstico da causa de recidiva dos sintomas, considerou-se : o tempo de recidiva dos sintomas após cardiomiotomia, a classificação radiológica do megaesôfago, e a presença ou ausência de esofagite de refluxo ao estudo endoscópico.

Na tabela 1 estão representados os parâmetros utilizados para 0 diagnóstico da causa de recidiva dos sintomas. 
Tabela 1 - Diagnóstico da causa de recidiva dos sintomas após cardiomiotomia

\begin{tabular}{lcccc}
\hline & \multicolumn{2}{c}{$\begin{array}{c}\text { Tempo de } \\
\text { recidiva dos } \\
\text { sintomas }\end{array}$} & Rx Esôfago & $\begin{array}{c}\text { Endoscopia } \\
\text { do esôfago }\end{array}$ \\
\hline Esofagite de refluxo & $>6$ meses & I , II , III , IV & $\begin{array}{c}\text { Esofagite de } \\
\text { refluxo }\end{array}$ \\
Miotomia incompleta & $<3$ a 6 meses & I, II , III & Ausente \\
Fibrose na área da miotomia & $>6$ meses & I, II , III & Ausente \\
Megaesôfago grupo IV & $<3$ a 6 meses & IV & Ausente \\
\hline
\end{tabular}

\subsection{5 - Técnica cirúrgica}

Todos os pacientes foram reoperados pela técnica de SERRA DÓRIA, (1970) abaixo descrita.

\subsubsection{1 - Preparo do paciente}

Os pacientes foram submetidos à limpeza do esôfago, no dia anterior ao procedimento .Consistia em lavagem do esôfago com soro fisiológico instilado através de uma sonda nasoesofágica $\mathrm{n}^{\circ}$ 18, injetando-se cerca de $200 \mathrm{ml}$ por vez e aspirando-se em seguida, até que o líquido retornasse limpo. Antibioticoterapia profilática era iniciada na indução anestésica ( cefalotina 1,0 g EV ou cefazolina 2,0 g EV). 


\subsubsection{2 - Técnica operatória}

Após anestesia geral, o paciente era colocado em decúbito dorsal horizontal com coxim na região dorsal, procedendo-se a seguir, da seguinte forma:

- incisão xifo-umbilical ou eventualmente até 2 a $3 \mathrm{~cm}$ abaixo da cicatriz umbilical, sempre que possível sobre a cicatriz da incisão já existente (figura 2);

- liberação de aderências decorrentes da operação anterior, com secção do ligamento triangular esquerdo do fígado (figura 3);

- exposição e isolamento do esôfago terminal após passagem de sonda nasogástrica. Tração suave do estômago para baixo, desfazendo-se a fundoplicatura, quando existente ( figura 4 );

- anastomose esôfago gástrica látero-lateral conforme técnica de GRÖNDHAL (1916) com um ou dois planos de sutura, com pontos separados de algodão 30 . Em três doentes esta sutura foi realizada com grampeador mecânico linear cortante de $75 \mathrm{~mm}$ (figuras 5,6 e 7 );

- hemigastrectomia, utilizando-se como referência uma linha que passava pela incisura angularis até a porção média da grande curvatura. Fechamento do coto duodenal em dois planos de sutura, com pontos separados de algodão 3-0 (figura 8 ); 
- anastomose gastrojejunal término-lateral em Y-de-Roux oralis totalis, précólica, anisoperistáltica, em dois planos de sutura contínua, com categute 2-0 cromado (Figura 8);

- anastomose jejuno-jejunal término-lateral a $40 \mathrm{~cm}$ da gastrojejunal, com pontos separados, sutura extramucosa empregando-se algodão 3-0 (Figura 9). A figura 10 mostra o aspecto final da operação;

- drenagem da cavidade abdominal, loja subepática, com dreno de Penrose exteriorizado por contra abertura no quadrante superior direito do abdome; fechamento da parede abdominal por planos: peritônio com sutura contínua de categute cromado 2-0, e aponeurose, com pontos separados de algodão 2-0; aproximação do subcutâneo com pontos separados de categute 2-0 simples e pele, com pontos separados de mononylon 4-0. 


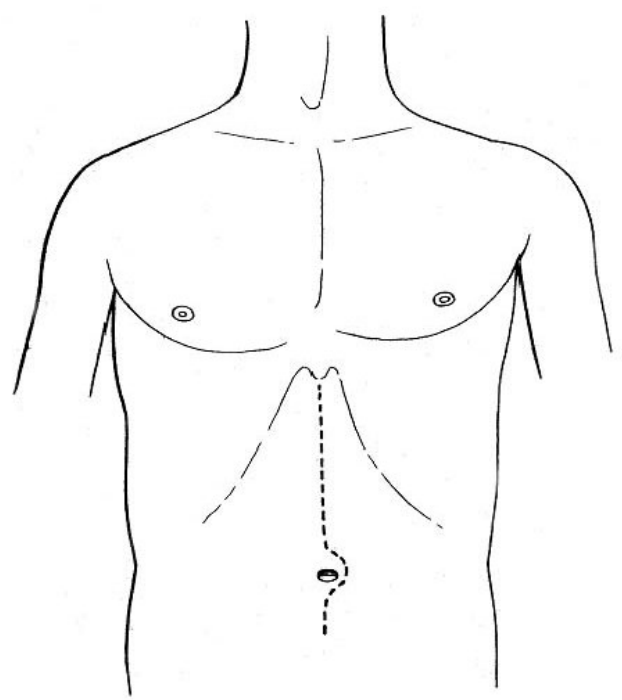

a

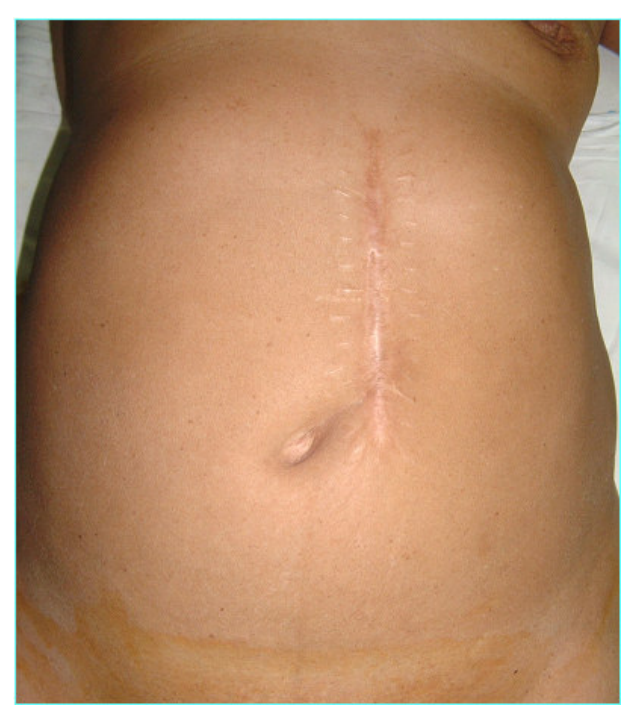

b

Figura 2 - Locais para realização da laparotomia:

a) preferencialmente mediana e, se necessário, com prolongamento infraumbilical.

b) sobre cicatriz de laparotomia já existente 

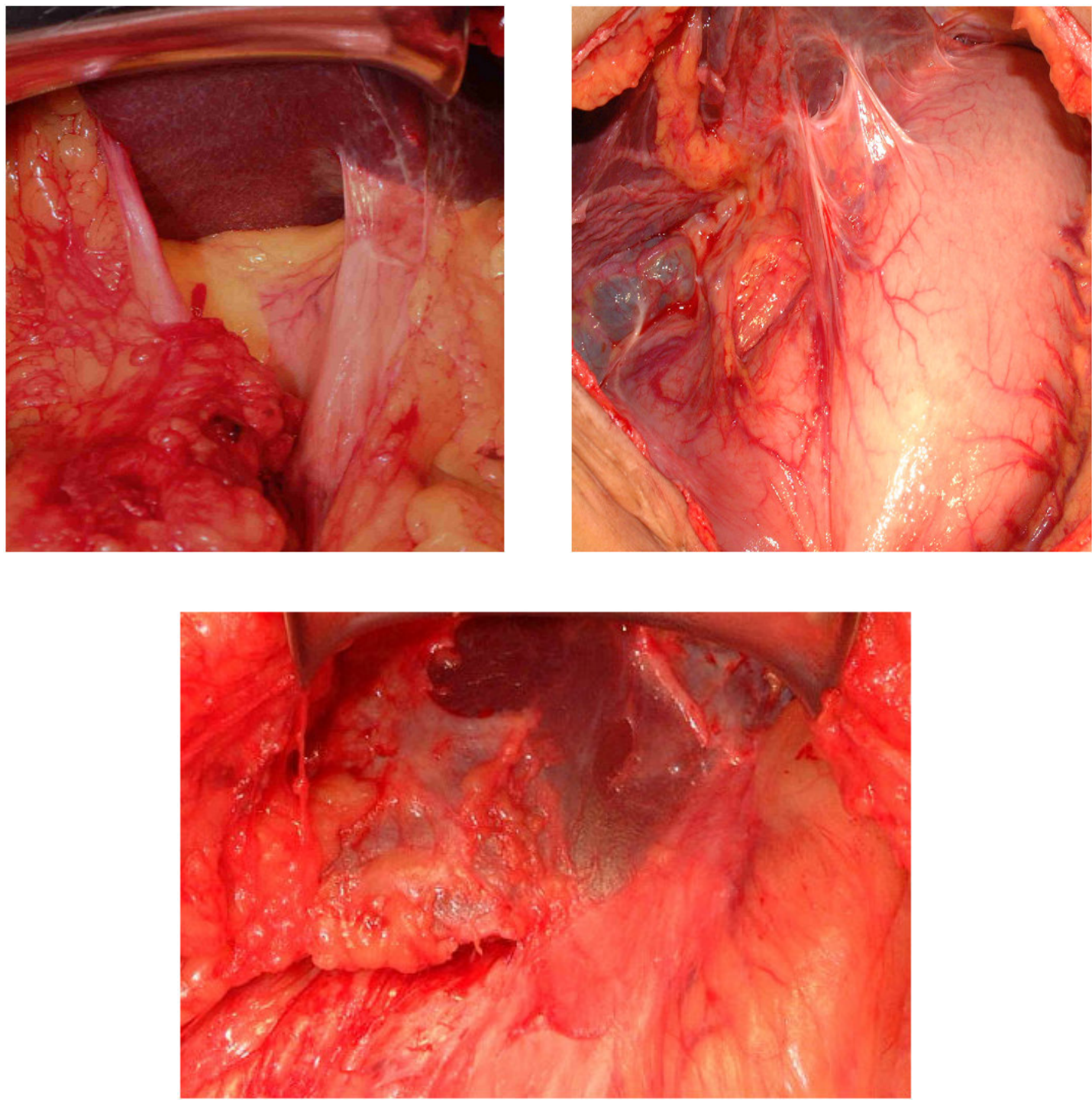

Figura 3 - As imagens representam aderências freqüentemente existentes nas reoperações para megaesôfago entre o estômago e estruturas adjacentes, principalmente com o fígado 

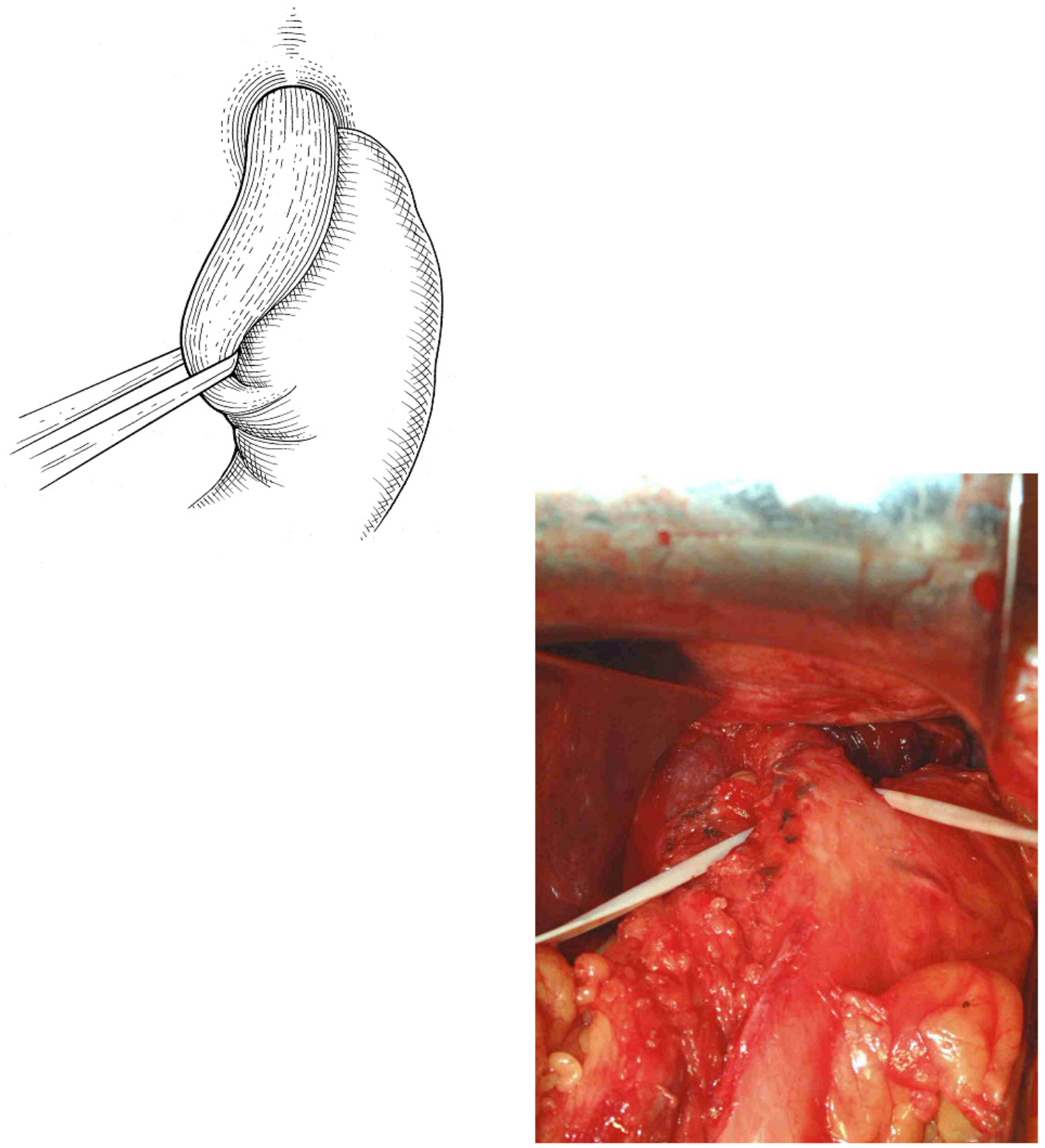

Figura 4 - Dissecção do esôfago distal com passagem de dreno de Penrose para tração 

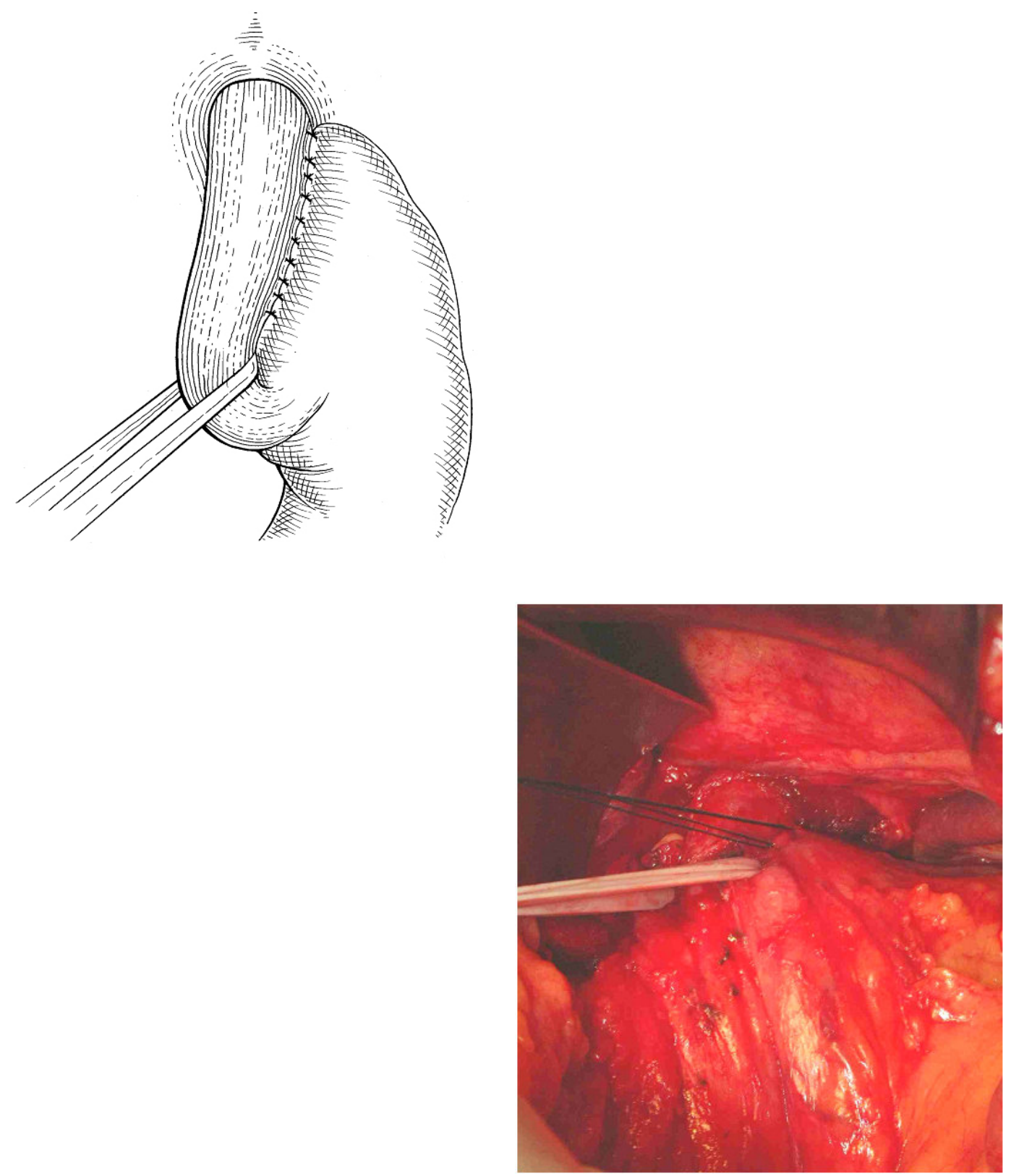

Figura 5 - Plicatura do fundo gástrico a face esquerda do esôfago distal 


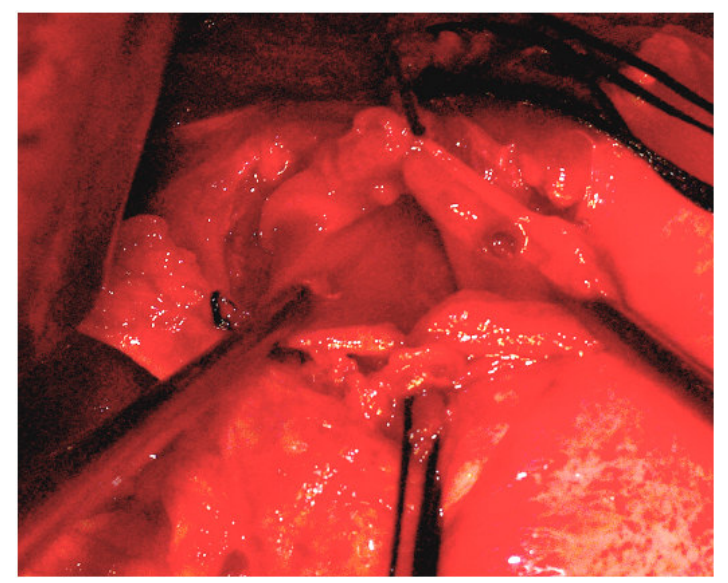

a

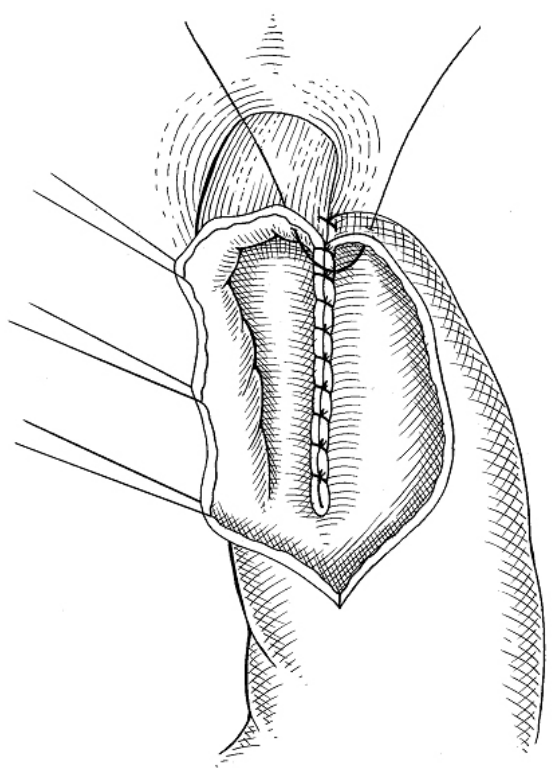

b

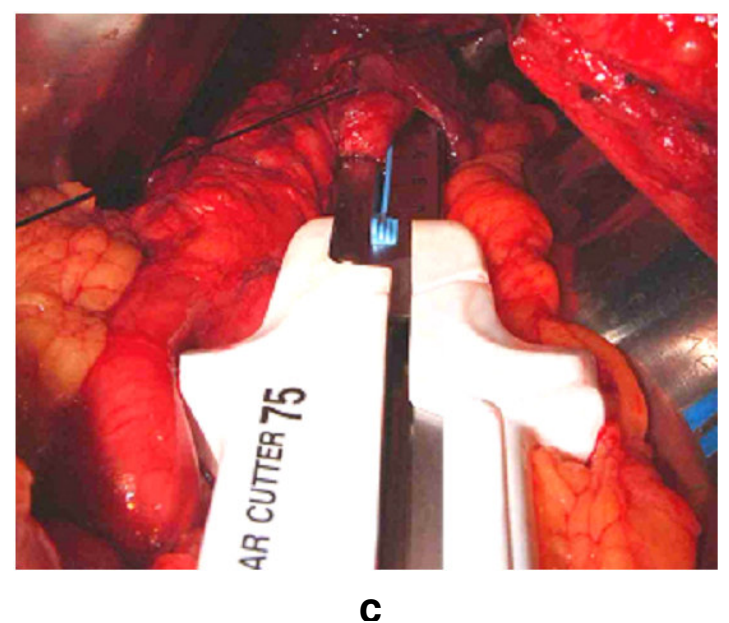

Figura 6 - Anastomose esofagogástrica látero-lateral:

a) realização de sutura posterior com pontos separados de algodão;

b) esquema da sutura do plano posterior;

c) anastomose esofagogástrica realizada com grampeador linear cortante de $75 \mathrm{~mm}$. 

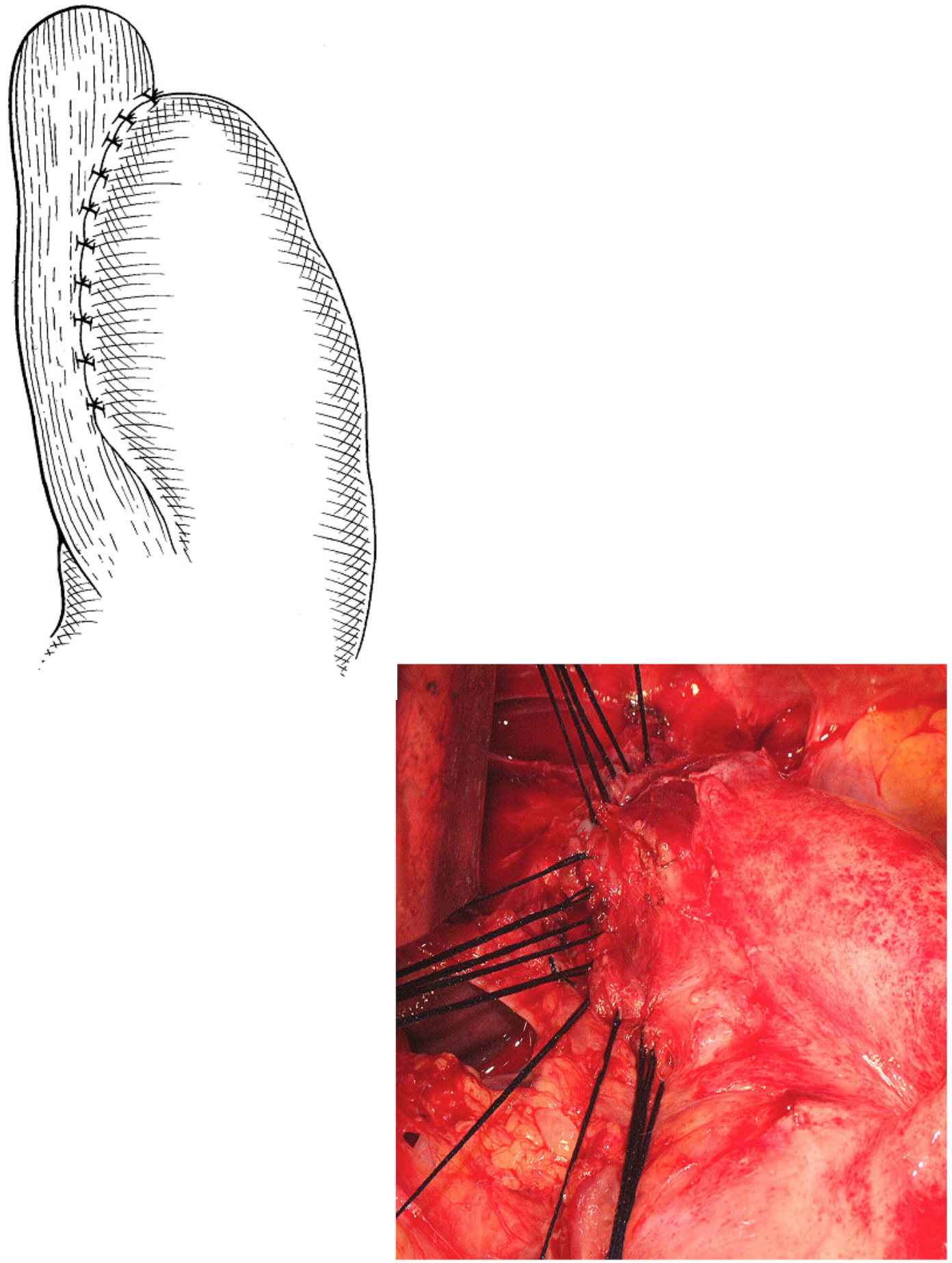

Figura 7 - Aspecto final da anastomose esofagogástrica 


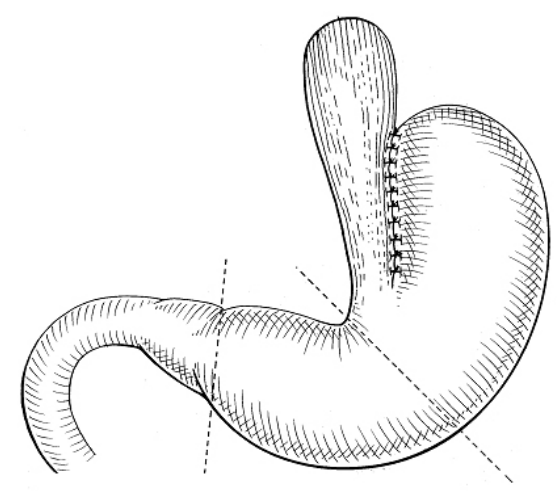

a
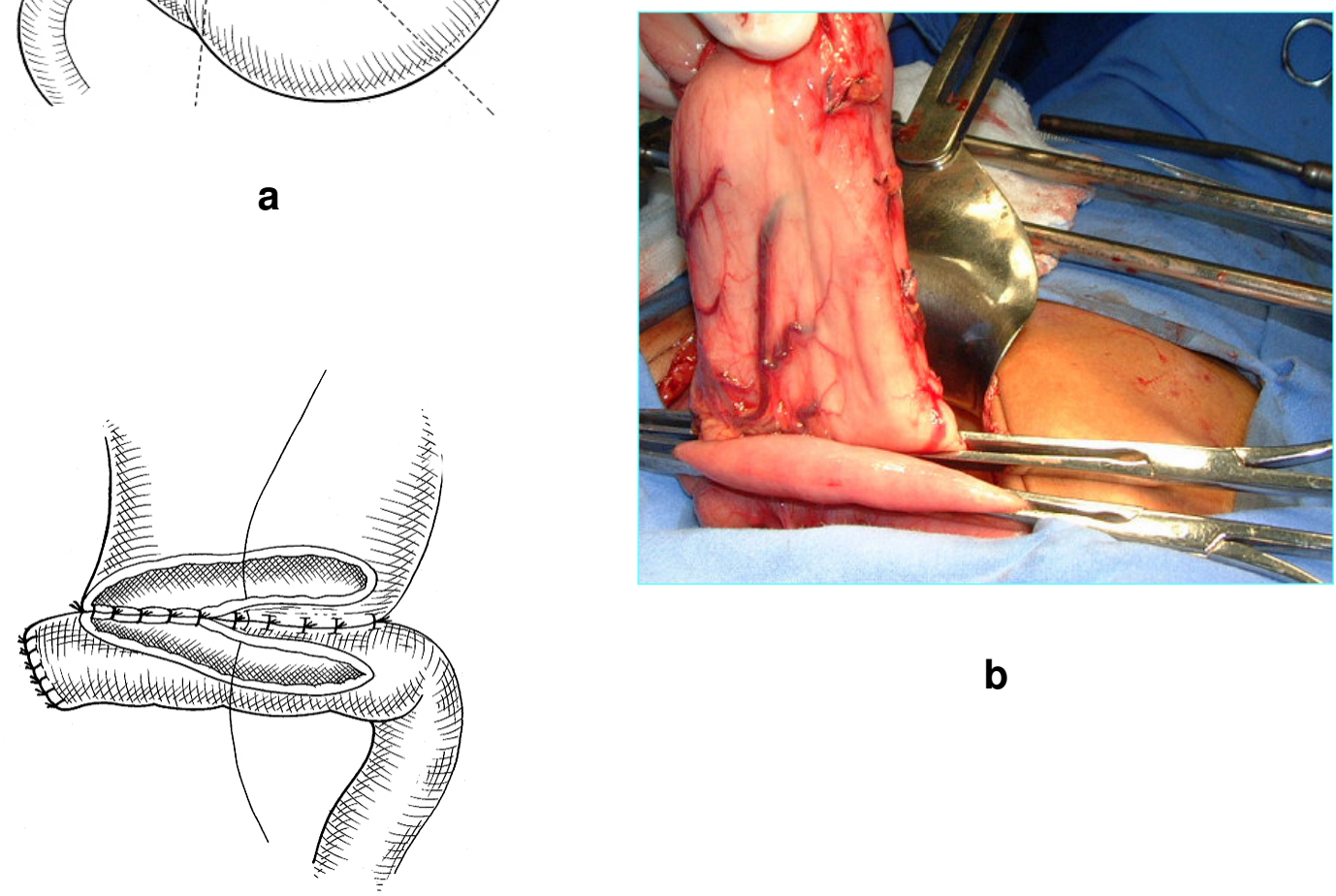

b

C

Figura 8 - Ressecção gástrica com anastomose gastrojejunal:

a) esquema mostrando o estômago a ser ressecado;

b) estômago e jejuno aprisionado com pinça de Abbadie para início da abertura;

c) anastomose gastrojejunal término-lateral, demonstrando as suturas seromuscular e muco-mucosa posterior 

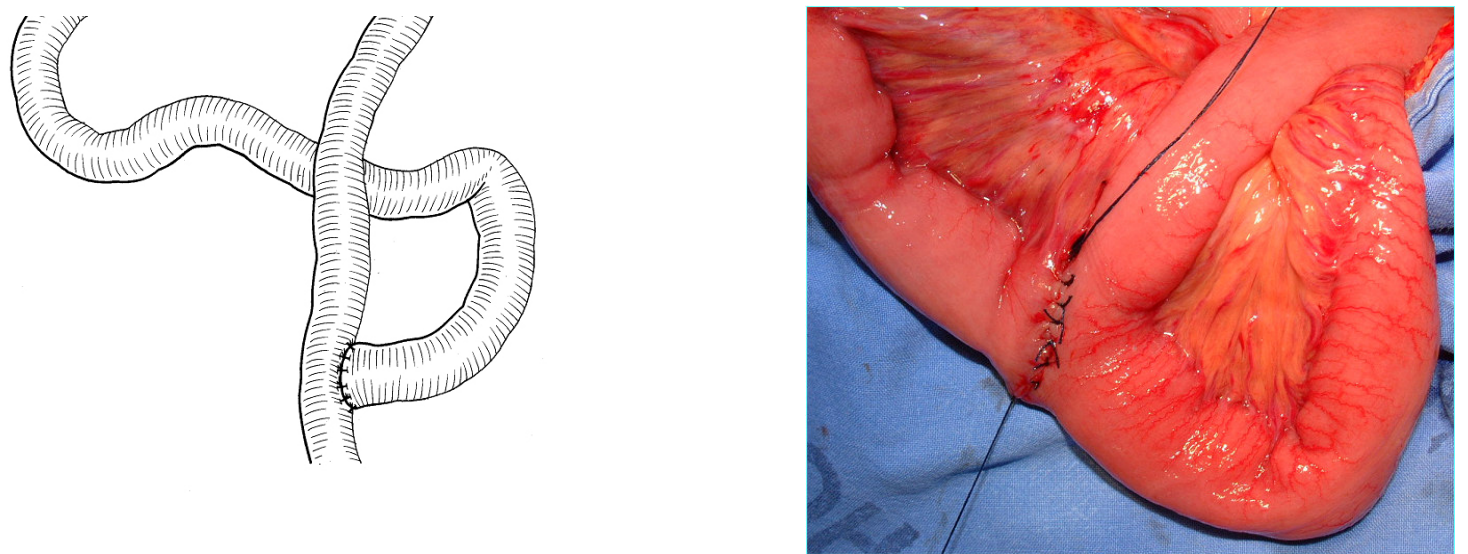

Figura 9 - Anastomose jejunojejunal término-lateral (Y-de-Roux) 40 cm abaixo da gastrojejunal

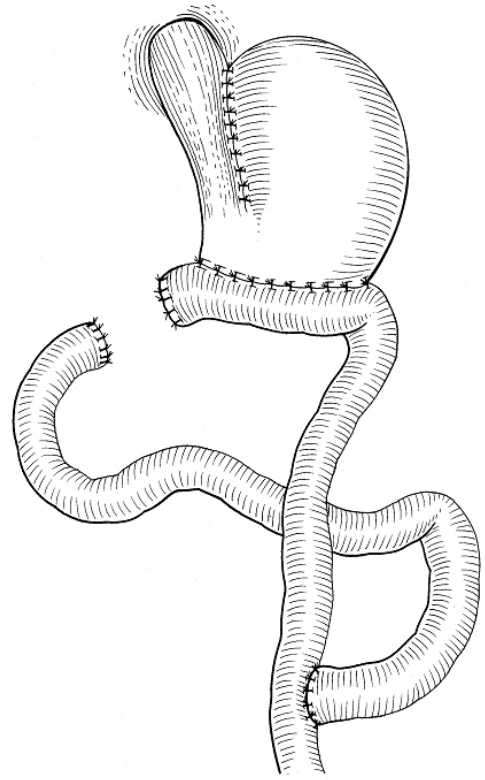

Figura 10 - Esquema do aspecto final da operação com visualização de todas as anastomoses 


\subsubsection{3 - Cuidados pós operatórios}

Os pacientes foram mantidos em jejum, com sonda nasogástrica, reposição hídrica, uso de analgésicos e antibiótico, este por 24 horas. Uma vez estabelecido o peristaltismo, geralmente no $3^{\text {ํ }}$ dia pós-operatório iniciava-se alimentação oral, progredindo-se de alimentos líquidos, para pastosos e, finalmente, dieta livre .

\subsection{6 - Complicações intra e pós-operatórias}

Foram avaliadas as complicações intra-operatórias, especialmente quanto às dificuldades de dissecção, devido as aderências da operação anterior e as pós-operatórias, até a alta do paciente

\subsection{7 - Seguimento pós-operatório}

Os pacientes foram avaliados em dois períodos:

imediato : $\quad$ - 30 a 60 dias após operação

tardio: - realizado de 6 a 108 meses (média $=22,3$ meses) após o procedimento cirúrgico.

Os pacientes foram avaliados sob o ponto de vista clinico (presença e intensidade da disfagia, regurgitação, pirose e peso), radiológico (calibre do 
esôfago de acordo c/ classificação de REZENDE et al., 1960) e endoscópico (presença ou ausência de esofagite de refluxo).

Os resultados observados foram comparados com os obtidos no préoperatório.

\subsection{8 - Análise estatística}

Para análise comparativa pré e pós-operatória em relação à avaliação clínica (disfagia , regurgitação e pirose ), radiológica e endoscópica, utilizou-se o teste de Wilcoxon

O nível de significância foi fixado em valor $\leq 0,05$ (5\%) 


\section{RESULTADOS}




\subsection{Resultados}

\section{1 - Diagnóstico da causa de recidiva}

Considerando-se os dados das avaliações clínica, radiológica e endoscópica pré-operatório e de acordo com os parâmetros seguidos na tabela 1 , os pacientes foram classificados em quatro causas principais de recidiva dos sintomas (tabela 2). Estes dados estão também referidos no anexo 1.

Nove (45\%) pacientes apresentavam esofagite de refluxo, um (5\%) miotomia incompleta, cinco (25\%), fibrose com cicatrização da miotomia e cinco(25\%), megaesôfago grupo IV. Três (15\%) pacientes que apresentavam esofagite de refluxo tinham também megaesôfago grupo IV. O refluxo foi considerado como causa principal de recidiva dos sintomas nestes pacientes.

Tabela 2 - Causa de recidiva dos sintomas após cardiomiotomia

\begin{tabular}{lll}
\hline \multicolumn{1}{c}{ Causa } & no & $\%$ \\
\hline Esofagite de refluxo & 9 & 45,0 \\
Miotomia incompleta & 1 & 5,0 \\
Cicatrização da miotomia & 5 & 25,0 \\
Megaesôfago grupo IV & 5 & 25,0 \\
\hline Total & 20 & 100,0 \\
\hline
\end{tabular}




\section{2- Complicações intra e pós-operatórias}

Todos os pacientes apresentavam aderências do estômago com estruturas vizinhas, que foram desfeitas sem maiores conseqüências. Em um doente houve perfuração do esôfago na face anterior, durante o isolamento do órgão. Esta abertura foi ampliada completando-se o procedimento com anastomose esofagogástrica latero-lateral.

O tempo de operação variou de 140 a 405 minutos (média $=246,2$ minutos) e a internação de oito a 42 dias ( média $=12$ dias).

As complicações pós-operatórias estão na tabela 3.

Dois (10\%) pacientes apresentaram fístula da anastomose esofagogástrica; ambos foram tratados com nutrição parenteral total até o seu fechamento. Receberam alta, respectivamente, no $22^{\circ}$ e $42^{\circ}$ dia pós-operatório . Dois (10\%) tiveram disfagia transitória e um ( 15\%), pneumotórax. Neste, houve abertura da pleura esquerda durante o isolamento de esôfago, que foi suturada, mas ocorreu pneumotórax logo após a operação. Procedeu-se drenagem torácica fechada com sucesso. Não houve mortalidade. 
Tabela 3 - Complicações intra e pós-operatórias da operação de Serra Dória para tratamento do megaesôfago já operado.

\begin{tabular}{lcc}
\hline \multicolumn{1}{c}{ Complicações } & № & $\%$ \\
\hline Disfagia - edema da anastamose & 2 & 10,0 \\
esofagogástica & & \\
Pneumotórax & 1 & 5,0 \\
Fístula & 2 & 10,0 \\
Óbito & 0 & \\
\hline
\end{tabular}

\subsection{Avaliação clínica}

No pré-operatório três (15\%) pacientes apresentam disfagia moderada e 17 (85\%) intensa. No pós-operatório imediato a avaliação mostrou que 16 (80\%) pacientes não tinham disfagia; quatro (20\%) apresentam disfagia leve (tabela 4). Houve melhora significativa da disfagia em relação ao pré-operatório $(p=0,001)$. 
Tabela 4 - Avaliação da disfagia no pré e pós-operatório imediato de pacientes com megaesôfago submetidos à operação de Serra Dória

\begin{tabular}{lcccc}
\multicolumn{2}{l}{20 pacientes } \\
\hline Disfagia & \multicolumn{2}{l}{ Pré-operatório } & \multicolumn{2}{c}{$\begin{array}{l}\text { Pós-operatório } \\
\text { Imediato }\end{array}$} \\
\hline Sem disfagia & $\mathrm{n}$ - & $\%$ & $\mathrm{n}^{\circ}$ & $\%$ \\
Leve & 0 & 0 & 16 & 80,0 \\
Moderada & 0 & 0 & 4 & 20,0 \\
Intensa & 3 & 15,0 & 0 & 0 \\
\hline Total & 17 & 85,0 & 0 & 0 \\
\hline
\end{tabular}

$p=0,001$

$\mathrm{Na}$ figura 11 pode-se observar que dos 17 pacientes que apresentavam disfagia intensa antes da operação, três passaram a apresentá-la sob a forma leve e 14 tornaram-se assintomáticos. Dos três doentes com disfagia moderada no pré-operatório, dois ficaram assintomáticos e um com disfagia leve. 
Figura 11 -Representação gráfica da avaliação da disfagia no pré e pósoperatório imediato -Operação de Serra Dória

20 pacientes

Sem disfagia

Disfagia leve

Disfagia Moderada

Disfagia intensa
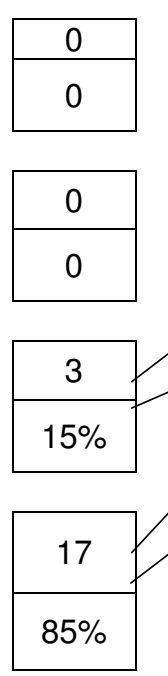

Pré-operatório

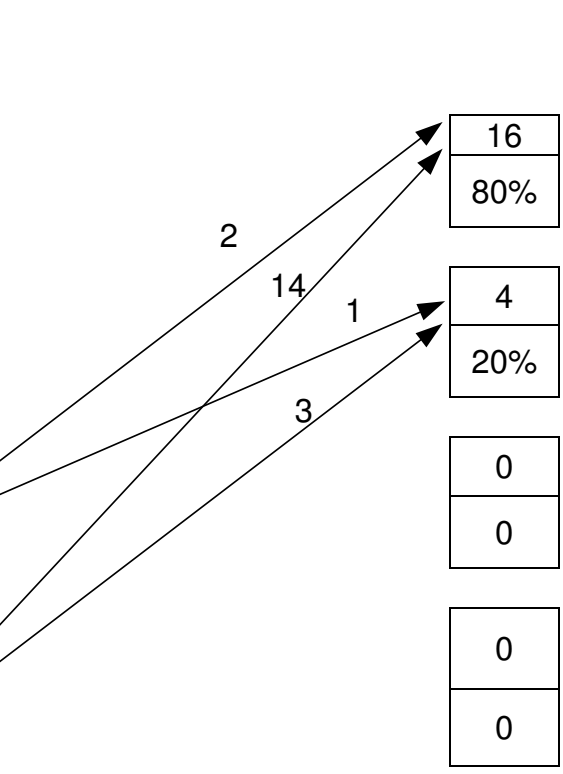

$\frac{\text { Pós-operatório }}{\text { imediato }}$

No pós operatório tardio 17 pacientes retornaram para avaliação . Todos apresentavam melhora da disfagia. Dez (58,5\%)não tinham dificuldade à deglutição; seis $(35,3 \%)$ apresentavam disfagia leve e um $(5,9 \%)$, moderada . Houve diferença significativa entre o pré e o pós-operatório tardio (tabela 5) $(p=0,001)$. 
Tabela 5 - Avaliação da disfagia no pré e pós-operatório tardio - Operação de Serra Dória

\section{7 pacientes}

\begin{tabular}{lcccc}
\hline & \multicolumn{2}{c}{ Pré-operatório } & \multicolumn{2}{c}{ Pós-operatório } \\
Disfagia & $\mathrm{n}-$ & $\%$ & $\mathrm{n}$ Tardio & $\%$ \\
& 0 & 0 & 10 & 58,8 \\
\hline Sem disfagia & 0 & 0 & 6 & 35,3 \\
Leve & 3 & 17,6 & 1 & 5,9 \\
Moderada & 14 & 82,4 & 0 & 0 \\
Intensa & 17 & 100,0 & 17 & 100,0 \\
\hline Total & & & &
\end{tabular}

No figura 12 pode-se observar que todos os pacientes melhoraram. Dos 14 pacientes com disfagia intensa, nove não a apresentavam; e quatro estavam com disfagia leve e um, moderada. 
Figura 12 - Representação gráfica da avaliação da disfagia no pré e pós-

$$
\begin{gathered}
\text { operatório tardio - Operação de Serra Dória } \\
17 \text { pacientes }
\end{gathered}
$$

Sem disfagia

Disfagia leve

Disfagia Moderada

Disfagia intensa
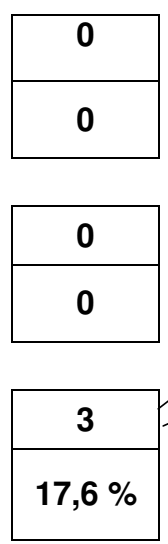

14

$82,4 \%$

Pré-operatório

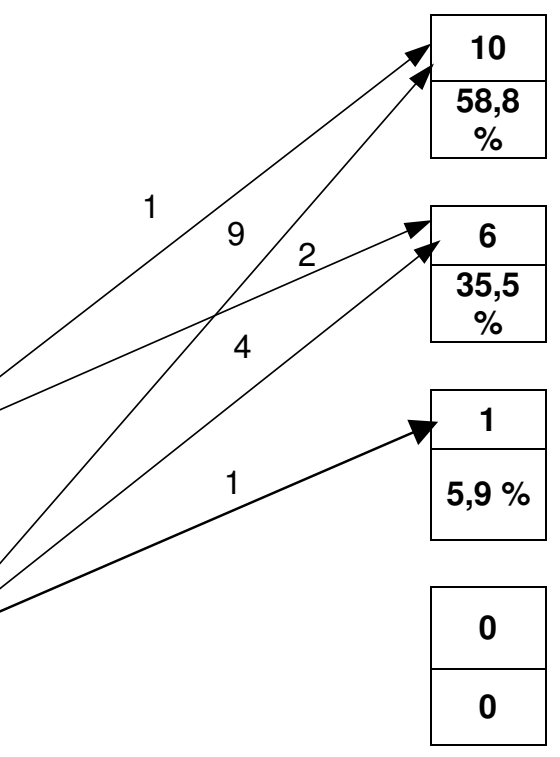

Pós-operatório tardio

A regurgitação foi freqüente no pré-operatório, ocorrendo em 16 (80\%) pacientes . No pós-operatório imediato foi referido somente por quatro (20\%) e, no tardio, por dois $(11,8 \%)$. Portanto, $80 \%$ dos pacientes estavam assintomáticos no pós-operatório imediato e $88,2 \%$, no tardio,. $\mathrm{Na}$ avaliação da regurgitação houve diferença significativa entre o pré e pós-operatório imediato $(p=0,001)$ e tardio $(p=0,001)$ (tabelas 6 e 7$)$. 
Tabela 6 - Avaliação da regurgitação no pré e pós-operatório imediato Operação de Serra Dória

20 pacientes

\begin{tabular}{lcccc}
\hline & \multicolumn{2}{c}{ Pré-operatório } & \multicolumn{2}{c}{ Pós-operatório } \\
& & & \multicolumn{2}{c}{ Imediato } \\
& $\mathrm{n}^{\mathrm{0}}$ & $\%$ & $\mathrm{n}$ - & $\%$ \\
\hline Presente & 16 & 80,0 & 4 & 20,0 \\
Ausente & 4 & 20,0 & 16 & 80,0 \\
\hline Total & 20 & 100,0 & 20 & 100,0 \\
\hline
\end{tabular}

$p=0,001$

Tabela 7 - Avaliação da regurgitação no pré e pós-operatório tardio Operação de Serra Dória

17 pacientes

\begin{tabular}{lcccc}
\hline & \multicolumn{2}{c}{ Pré-operatório } & \multicolumn{2}{c}{ Pós-operatório } \\
& Regurgitação & \multicolumn{3}{c}{ tardio } \\
& $\mathbf{n}^{\mathbf{0}}$ & $\%$ & $\mathrm{n}^{\circ}$ & $\%$ \\
\hline Presente & 13 & 76,5 & 2 & 11,8 \\
Ausente & 4 & 23,5 & 15 & 88,2 \\
\hline Total & 17 & 100,0 & 17 & 100,0 \\
\hline
\end{tabular}

$p=0,005$ 
$\mathrm{Na}$ avaliação pré-operatória observou-se a presença de pirose em $65 \%$ dos pacientes. Somente dois (10\%) relataram pirose no pós operatório imediato e três $(17,6 \%)$, no tardio . Houve melhora significativa da pirose tanto no pósoperatório imediato $(p=0,005)$ como tardio $(p=0,005) \quad$ ( Tabelas 8 e 9$)$.

Tabela 8 - Avaliação da pirose no pré e pós-operatório imediato Operação de Serra Dória

20 pacientes

\begin{tabular}{|c|c|c|c|c|}
\hline \multirow{2}{*}{ Pirose } & \multicolumn{2}{|c|}{ Pré-operatório } & \multicolumn{2}{|c|}{$\begin{array}{l}\text { Pós-operatório } \\
\text { Imediato }\end{array}$} \\
\hline & no & $\%$ & no & $\%$ \\
\hline Presente & 13 & 65,0 & 2 & 10,0 \\
\hline Ausente & 7 & 35,0 & 18 & 90,0 \\
\hline Total & 20 & 100,0 & 20 & 100,0 \\
\hline
\end{tabular}

$\mathrm{p}=\mathbf{0 , 0 0 5}$

Tabela 9- Avaliação da pirose no pré e pós-operatório tardio - Operação de Serra Dória

17 pacientes

\begin{tabular}{|c|c|c|c|c|}
\hline \multirow[t]{2}{*}{ Regurgitação } & \multicolumn{2}{|c|}{ Pré-operatório } & \multicolumn{2}{|c|}{$\begin{array}{c}\text { Pós-operatório } \\
\text { Tardio }\end{array}$} \\
\hline & no & $\%$ & no & $\%$ \\
\hline Presente & 10 & 58,8 & 3 & 17,6 \\
\hline Ausente & 7 & 41,2 & 14 & 82,4 \\
\hline Total & 17 & 100,0 & 17 & 100,0 \\
\hline
\end{tabular}


Vale ainda ressaltar que dois(10\%) pacientes apresentaram síndrome de dumping sob a forma leve, caracterizada por mal estar após a alimentação . Estes sintomas desapareceram no pós-operatório tardio. Um paciente apresentou anemia no $108^{\circ}$ mês após operação.

A avaliação do peso foi realizada em 17 pacientes . Nesta avaliação observou-se que cinco(29,4\%) apresentaram ganho de peso, seis(35,4\%) o mantiveram e seis $(35,4 \%)$ perderam. A média de ganho de peso foi $11,8 \mathrm{~kg}$ e a perda, de $7,7 \mathrm{~kg}$ (tabela 10).

Tabela 10 - Variação do peso entre o pré e pós-operatório tardio Operação de Serra Dória

17 pacientes

\begin{tabular}{lccc}
\hline \multicolumn{1}{l}{ Peso } & $\mathrm{n}$ - & $\%$ & $\begin{array}{c}\text { Média } \\
(\mathrm{kg})\end{array}$ \\
\hline Manutenção & 6 & 35,3 & \\
Aumento & 5 & 29,4 & 11,8 \\
Diminuição & 6 & 35,3 & 7,7 \\
\hline Total & 17 & 100,0 & \\
\hline
\end{tabular}

\subsection{Avaliação radiológica}

O avaliação radiológica pré e pós-operatória foi realizada em 13 (65\%)pacientes. Nesta avaliação observou-se que no pré-operatório, seis 
(46,2\%) apresentavam megaesôfago grupo III e seis (46,2 \%), grupo IV; Um (7,6\%), apresentava imagem radiológica de megaesôfago grupo II. O exame radiológico de controle foi sempre realizado após o sexto mês de pósoperatório. Em seis $(46,2 \%)$ doentes o aspecto radiológico era de megaesôfago grupo II, e em quatro $(30,7 \%)$ de grupo III; três $(23,1 \%)$ doentes mantiveram megaesôfago grupo IV( tabela 11). Houve diminuição significativa do calibre do esôfago após operação $(p=0,003)$.

Tabela 11 - Avaliação radiológica no pré e pós-operatório tardio - Operação de Serra Dória

13 pacientes

\begin{tabular}{lcccc}
\hline & \multicolumn{2}{c}{ Pré-operatório } & \multicolumn{2}{c}{ Pós-operatório } \\
Classificação megaesôfago & \multicolumn{2}{c}{ tardio } \\
& no & $\%$ & no & $\%$ \\
\hline Grupo II & 1 & 7,6 & 6 & 46,2 \\
Grupo III & 6 & 46,2 & 4 & 30,7 \\
Grupo IV & 6 & 46,2 & 3 & 23,1 \\
\hline Total & 13 & 100,0 & 13 & 100,0 \\
\hline$p=0,003$ & & & &
\end{tabular}

As alterações do calibre do esôfago estão representadas na figura 13. Nota-se diminuição do calibre do esôfago após a operação em sete pacientes e manutenção do mesmo calibre, em seis. Dos que apresentavam megaesôfago grupo IV, em três( $50 \%$ ) houve diminuição do calibre do esôfago. 
Figura 13 - Representação gráfica da avaliação radiológica no pré e pósoperatório tardio - Operação de Serra Dória

\section{Grupo II}

Grupo III

Grupo IV

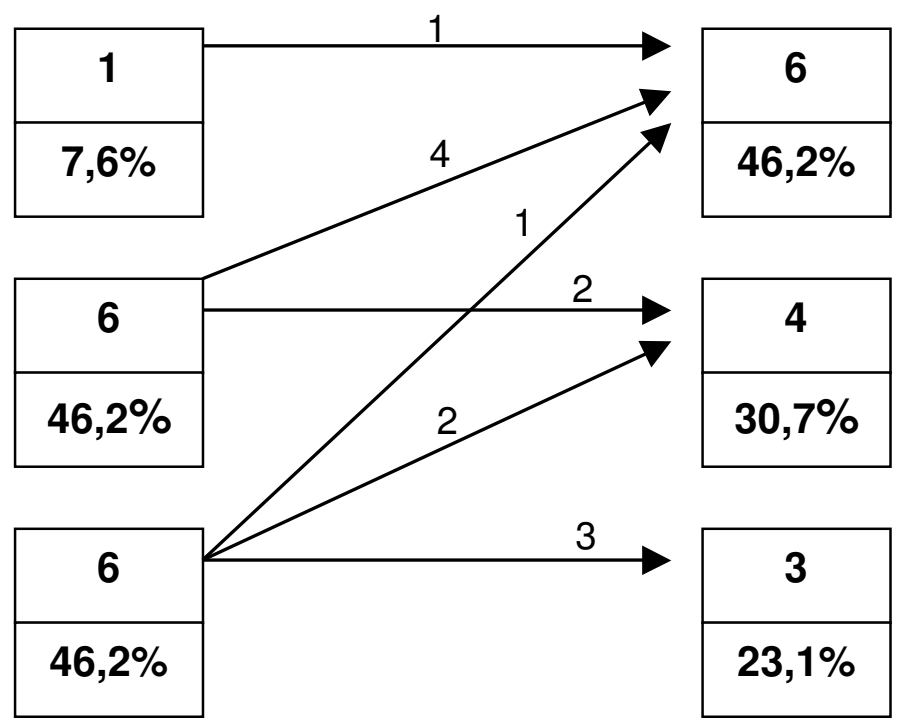

Pré-operatório

Pós-operatório tardio

\subsection{Avaliação endoscópica}

Avaliação endoscópica pré e pós-operatória tardia foi realizada em 17 pacientes. No pré-operatorio oito $(47,1 \%)$ tinham mucosa normal e nove $(52,9 \%)$ apresentavam esofagite de refluxo com edema ou até erosões. No pós-operatório $12(70,6 \%)$ pacientes tinham mucosa normal e cinco $(29,4 \%)$, esofagite de refluxo. Todos os pacientes com esofagite foram tratados com bloqueador $\mathrm{H} 2$ ou inibidor de bomba de prótons, encontrando-se assintomáticos (tabela 12). Embora houvesse tendência à diminuição da esofagite no pós-operatório, não se observou diferença significativa entre a avaliação pré e pós-operatória ( $\mathrm{p}=0,157)$. 
Tabela 12 - Avaliação endoscópica no pré e pós-operatório tardio Operação de Serra Dória

17 pacientes

\begin{tabular}{lcccc}
\hline & \multicolumn{2}{c}{ Pré-operatório } & \multicolumn{2}{c}{ Pós-operatório } \\
Esofagite & \multicolumn{2}{c}{ Tardio } \\
& 0 & $\%$ & $\mathrm{n}^{\circ}$ & $\%$ \\
\hline Presente & 9 & 52,9 & 5 & 29,4 \\
Ausente & 8 & 47,1 & 11 & 70,6 \\
\hline Total & 17 & 100,0 & 17 & 100,0 \\
\hline $\mathrm{p}=0,257$ & & & &
\end{tabular}

$\mathrm{Na}$ figura 14 observa-se que dos nove pacientes que apresentavam esofagite de refluxo no pré-operatório, três a mantiveram; dois novos casos apareceram após a operação. O tratamento cirúrgico proporcionou melhora da esofagite em seis pacientes. 
Figura 14 - Avaliação endoscópica no pré e pós-operatório tardio Operação de Serra Dória

17 pacientes

\section{Com esofagite}

Sem esofagite

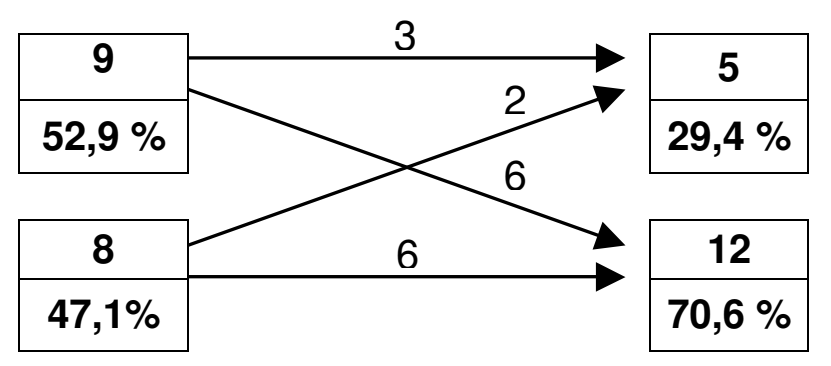

Pré-operatório

Pós-operatório tardio 
DISCUSSÃO 


\subsection{Discussão}

Historicamente, a primeira proposta para tratamento da acalásia foi feita por GOTTSTEIN em (1901) ( apud ELLENBOGEM, 1979), que a estabeleceu através da cardiomiotomia. Entretanto foi HELLER (1913) (apud ELLENBOGEM, 1979) quem consagrou o procedimento, realizando-a na face anterior e posterior do esôfago.

A facilidade de realização técnica da miotomia apenas na parede anterior, quer por via abdominal (GOENVELDT, 1918) ( apud ELLENBOGEM, 1979), quer por via torácica (ZAAJER, 1923) ( apud ELLENBOGEM, 1979), tornou esta operação preferencial para tratamento da acalásia . No entanto, por representar secção da musculatura do EIE, alterando os mecanismos de contenção do refluxo, este procedimento favorecia o aparecimento de refluxo gastroesofágico.

$\mathrm{Na}$ tentativa de corrigir o refluxo alguns autores acrescentaram às miotomias, fundoplicatura, criando assim mecanismo anti-refluxo, obtendo melhores resultados (DOR et al., 1962; JEKLER e LOKTHA, 1967; PINOTTI et al., 1974).

Quando é realizada somente a cardiomiotomia, há ocorrência de esofagite de refluxo em 17 a 30\% dos pacientes ( STIPA e BELSEY, 1976; CHAIB et al.1977; BOULEZ et al., 1981; CSENDES, et al., 1981). A associação de fundoplicatura à cardiomiotomia reduz as taxas de esofagite para valores entre 2,8\% e 5\% (ELLENBOGEM 1979; FELIX 1994). Como no megaesôfago, o poder de clareamento do esôfago está prejudicado pela diminuição ou, em alguns 
casos, ausência de peristaltismo esofágico, a tolerância do órgão ao refluxo está diminuída. Este quadro é agravado com a alteração do mecanismo de contenção anti-refluxo após a operação. A realização de miotomia aumenta a exposição do esôfago à secreção ácida ou alcalina, propiciando complicações futuras, destacando-se entre elas o processo inflamatório da mucosa esofágica, pirose e recidiva da disfagia.

Embora a cardiomiotomia com fundoplicatura no tratamento do megaesôfago não avançado apresente bons resultados em $85 \%$ a $97,6 \%$ dos doentes (PINOTTI et al., 1974; 1991b; ELLIS Jr. e GIBB, 1975; FEKETE e LORTAT-JACOB, 1977; CZENDES, 1991; GAYET E FEKETE, 1991; FELIX, 1994; PATTI et al., 1995; HERBELLA et al. 1999), pode ocorrer manutenção da disfagia. Sua ocorrência não diminuiu ao longo dos anos, a despeito da maior experiência dos cirurgiões com a técnica e com o desenvolvimento de instrumentais cirúrgicos.

Outras causas de recidiva da disfagia após a cardiomiotomia são citadas (ELLIS Jr. e GIBB., 1975; FEKETE e LORTAT JACOB, 1977; MERCER, et al., 1986; ELLIS Jr. et al.,1986; GAYET e FEKETE, 1991; SERRA, 1995; PINOTTI e FELIX, 1999):

-cardiomiotomia incompleta - representada pela secção inadequada dos feixes musculares do EIE em profundidade ou em extensão; como conseqüência, a disfagia permanece inalterada logo após a operação com melhora pouco significativa;

-cicatrização com fibrose na região da miotomia - a reaproximação das bordas da miotomia com fibrose determina recidiva da disfagia em pósoperatório relativamente tardio. A realização de miotomia sem retirada de fita 
muscular, o sangramento nesta área e as lesões da mucosa, mesmo que reconhecidas e tratadas no momento da operação, seriam os principais fatores causais desta recidiva;

-má indicação da técnica de cardiomiotomia em megaesôfago do

grupo IV- o esôfago atônico não apresenta esvaziamento adequado, determinando um período de melhora da disfagia muito curto (PINOTTI et al., 1979; DEL GENIO et al. 1995; SERRA et al., 1998; PINOTTI e FELIX, 1999).

-migração do fundo gástrico para o tórax - determinado pela diminuição do calibre esofágico em relação ao hiato diafragmático, após cardiomiotomia além da liberação dos fatores de fixação do estômago à cavidade abdominal, entre as quais a membrana frenoesofágica e os vasos breves;

Assim, fica patente a necessidade de se conhecer a causa da recidiva, para que o tratamento seja adequado (PINOTTI et al.,1979; CECCONELLO et al., 1988; SERRA, 1995; SERRA et al., 1998; PINOTTI e FELIX, 1999).

Existem dificuldades para se determinar as causas da recidiva da disfagia após tratamento cirúrgico do megaesôfago, conforme demonstraram ELLIS Jr et al. (1986). Estes autores utilizaram como parâmetros nesta tentativa, o histórico da cirurgia prévia, o tempo de recidiva dos sintomas, e os achados durante a reoperação. Outros autores utilizaram como critérios, tempo de aparecimento dos sintomas, avaliação endoscópica e radiológica (FEKETE et al., 1977), medida da pressão do EIE através de eletromanometria esofágica préoperatório(PINOTTI et al.,1979; CECCONELLO et al., 1988; SERRA et al , 1996; PINOTTI e FELIX, 1999) ou intra-operatória (DEL GENIO et al. 1995) e Phmetria de $24 \mathrm{~h}$ (DEL GENIO et al. 1995). 
Neste estudo foram utilizados como parâmetro para determinação de causa da recidiva dos sintomas: o tempo de reaparecimento dos sintomas após a operação, a avaliação radiológica, observando-se o grau de dilatação do esôfago, e endoscópica, a fim de se estudar as alterações da mucosa.

Uma vez que a disfagia ocorre em todos os pacientes com megaesôfago, ela é parâmetro seguro para a determinação do tempo de evolução da doença e da recidiva. Baseados nestes parâmetros foram encontrados como causa da recidiva: esofagite de refluxo em nove pacientes (45\%), miotomia incompleta em um (5\%), cicatrização da miotomia em cinco $(25 \%)$ e miotomia no megaesôfago grupo IV em cinco (25\%). . Em três pacientes (15\%) que apresentavam associação de megaesôfago grupo IV e esofagite de refluxo, esta foi considerada como causa da recidiva. PINOTTI e FELIX (1999) observaram em 118 pacientes as seguintes causas da recidiva dos sintomas: miotomia incompleta em 23 (34,7\%), cicatrização da miotomia em 16 (13,6\%), esofagite de refluxo em 36 (30,5\%), dolicomegaesôfago em 23 (19,5\%) e migração da fundoplicatura para o tórax em dois $(1,7 \%)$.

Baseado neste estudo e nos resultados encontrados por PINOTTI, et al., (1979); FEKETE et al., (1982); CECCONELLO, et al, (1988); GAYET e FEKETE, (1991); SERRA et al., (1996); PINOTTI e FELIX, (1999), pode-se concluir que a má indicação da cardiomiotomia em megaesôfago do grupo IV ou a realização da mesma de forma inadequada são os principais responsáveis pelo insucesso da operação. Ambas se manifestam por recidiva precoce da disfagia. A esofagite conseqüente ao refluxo e à cicatrização com fibrose na área da cardiomiotomia se caracterizam por recidiva mais tardia dos sintomas. 
Quase metade dos pacientes estudados tiveram como causa de recidiva dos sintomas, esofagite de refluxo. Isto ocorreu provavelmente porque na região de Goiânia utilizava-se, até recentemente, cardiomiotomia ampla sem retirada de fita muscular, associada à agudização do ângulo de Hiss, como proposta por LORTAT JACOB (1956) para tratamento do refluxo gastroesofágico. A migração da válvula para o tórax relatado por alguns autores (ELLIS Jr. et al. 1986; CECCONELLO et al., 1998; HERBELLA et al. 1999; PINOTTI e FELIX, 1999), não foi verificada em nenhum dos pacientes deste estudo.

Além das cardiomiotomias, operações mais antigas, chamadas de cardioplastias como as de HEYROVSKY (1913)( apud ELLEMBOGEM, 1979) e GRÖNDAHL (1916)( apud CHRISTMANN-OTTOLENGHI, 1975), ou mais recentes, como a de THAL e HATAFUKU (1965), empregadas para tratamento do megaesôfago, também se acompanham de recidiva dos sintomas. Estas oferecem resultados precários a curto e médio prazo devido principalmente a refluxo gastroesofágico, e mais tardiamente, a estenose e esôfago de Barret (FAROOQ e KEREN, 1987; CECCONELLO et al.1990) com recidiva da disfagia. A operação de THAL e HATAFUKU (1965) é utilizada ainda em vários locais do Brasil (BARBOSA et al, 1981; BARBOSA et al. 1989; FERRAZ et al, 2001) para tratamento inicial do megaesôfago ou em reoperações.

Para tratar esofagite de refluxo intensa em doentes com megaesôfago previamente submetidos a cardioplastia tipo GRÖNDAHL (1916) (apud CHRISTMANN-OTTOLENGHI, 1975), HOLT e LARGE, em 1961, realizaram em segunda operação, gastrectomia parcial em Y-de-Roux com vagotomia, relatando melhora imediata dos sintomas, sem evidência de esofagite de refluxo no pós-operatório. O princípio da reconstrução em Y-de-Roux foi 
introduzido por WOLFLER( apud POWELL et al., 1983) no $12^{\circ}$ Congresso de Cirurgiões da Alemanha em 1881. É, entretanto creditado a ROUX (1893) ( apud POWELL et al., 1983), o seu emprego mais amplo, com o objetivo de tratar vômitos biliosos após gastrectomia. A realização de jejuno-jejunoanastomose 45 a $60 \mathrm{~cm}$ abaixo da anastomose gastrojejunal reduz ou elimina o refluxo de bile para o estômago (POWELL et al, 1983). A gastrectomia com vagotomia reduz o ácido e diminui a ocorrência de úlcera péptica jejunal (HERRINGTON e SAWYERS, 1977; MENGUY, 1978).

Após o trabalho de HOLT e LARGE (1961), SERRA DÓRIA et al (1970, 1972) e SERRA DÓRIA ( 1973) passaram a empregar no Brasil, para tratamento inicial do megaesôfago, a associação de cardioplastia a GRÖNDAHL (1916)( apud CHRISTMANN-OTTOLENGHI, 1975) com gastrectomia parcial em Y-de-Roux, obtendo bons resultados em 130 pacientes nos quais foi empregada.

Nesta operação como em outras para megaesôfago, deve ser realizada ampla exposição do esôfago intra-abdominal, devendo-se estender a dissecção no sentido proximal até a área dilatada do órgão, que é facilmente identificada. $\mathrm{O}$ nervo vago, principalmente o ramo anterior, deve ser isolado; no entanto, em casos com dificuldade técnica pode ser seccionado, como nos pacientes com fibrose intensa na região.

Há, nas reoperações sobre a transição esofagogástrica, maior probabilidade de lesão esofágica, devido a aderências deste órgão com estruturas vizinhas. A liberação deve ser, portanto, cuidadosa. O acesso do esôfago intramediastinal por frenotomia mediana (PINOTTI, 1976), permite, se necessário, acesso ao esôfago fora da área com fibrose propiciando melhor visualização e segurança na dissecção das estruturas desta região. Ainda com a 
finalidade de facilitar a identificação e dissecção do esôfago, utilizou-se sonda nasogástrica na luz do órgão.

Não houve necessidade de ligadura de vasos curtos do estômago a fim de evitar tensão na anastomose esofagogástrica. Ela pode ser realizada tanto com sutura manual ou com grampeador mecânico. Nos três últimos pacientes, esta foi realizada com grampeador mecânico, levando diminuição do tempo cirúrgico.

A reconstituição do trânsito após a ressecção gástrica foi feita por anastomose gastrojejunal; por ser mais rápida, foi realizada em situação précólica, com anastomose jejuno-jejunal em Y-de-Roux pelo menos $40 \mathrm{~cm}$ abaixo da anastomose gastrojejunal.

Mesmo em se tratando de uma operação mais demorada, devido à necessidade de liberação de aderências da operação anterior e realização de três anastomoses, o tempo operatório variou de 140 a 405 minutos (média = 246,2 minutos).

Dentre as complicações intra-operatórias encontradas nas operações do esôfago por via abdominal, a lesão de pleura ocorre quando se deseja exposição ampla da porção distal do órgão levando, freqüentemente à formação de derrames pleurais. Os índices variam de $22,2 \%$ a $50,0 \%$ na esofagectomia sem toracotomia (PINOTTI, 1977; PINOTTI et al., 1981; ANDREOLLO, et al, 1988; CECCONELLO et al., 1988; ORRINGER \& STIRLING, 1989), podendo ocorrer também na cirurgia laparoscópica (4\%) segundo DOMENE( 1996)

No presente estudo um paciente apresentou lesão de pleura no peroperatório: a sutura da lesão foi realizada imediatamente após o seu reconhecimento. O paciente desenvolveu, entretanto, pneumotórax, havendo 
necessidade de drenagem torácica pós-operatória. Assim, sugere-se que nas lesões de pleura os pacientes sejam invariavelmente drenados ainda no intraoperatório.

A principal complicação pós-operatória foi fístula da anastomose esofagogástrica, que ocorreu em dois pacientes (10\%). Ambos foram conduzidos com nutrição parenteral total e evoluíram bem. Provavelmente o aparecimento destas fístulas esteve relacionado à dificuldade de dissecção da transição esofagogástrica, em razão das aderências resultantes da operação anterior. Um dos pacientes tinha sido submetido a duas operações prévias e o outro apresentava esofagite de refluxo. Este fato foi também observado por MENDELSSONH(1984) que referiram maior ocorrência de fístulas, quando realizaram operação de THAL e HATAFUKU (1965) em 17 pacientes que haviam sido submetidos previamente a mais de uma operação para tratamento do megaesôfago.

SERRA DORIA et al (1973) em 130 pacientes operados por cardioplastia a GRÖNDAHL (1916) ( apud CHRISTMANN-OTTOLENGHI, 1975) associada à gastrectomia em Y-de-Roux não observaram fístula. GOLDEMBERG (1973) também não as observou, em 11 pacientes operados pela mesma técnica, onde associou também vagotomia troncular.

A operação é segura, não havendo óbitos na presente série. Somente um dos pacientes necessitou internação em unidade de terapia intensiva, devido à doença pulmonar obstrutiva crônica. É possível que com o aumento de número de casos operados, outros pacientes necessitem de atendimento intensivo no pós-operatório, devido à cardiopatia freqüentemente associada ao megaesôfago chagásico. 
O tempo de internação hospitalar variou de 8 a 42 dias, com tempo médio de 12 dias. O aumento do tempo de internação foi decorrente do tratamento de fístula em dois pacientes. A permanência hospitalar foi de 22 e 42 dias, respectivamente. A predominância foi de alta hospitalar até o $10^{\circ}$ dia de pós operatório.

Vários autores têm utilizado critério seletivo para a indicação da técnica empregada na correção da recidiva dos sintomas (PATRICK et al, 1971; PINOTTI et al., 1979; FEKETE et al., 1982b; PERACHIA et al, 1986; ELLIS et al, 1986; JAMIESON, 1991; SERRA et al., 1998; FELIX et al., 1989; PINOTTI e FELIX, 1999). Nas miotomias incompletas ou com fibrose há uma tendência em se realizar nova miotomia (PINOTTI et al., 1979; MERCER e HILL, 1986; SERRA et al., 1996, 1998) no local da anteriormente realizada ou ao lado daquela. Nos pacientes que apresentam megaesôfago grupo IV caberia somente a ressecção esofágica (PINOTTI et at, 1979).

Algum grau de disfagia pode persistir após tratamento cirúrgico conservador do megaesôfago podendo ser explicado pelas alterações motoras já existentes no esôfago, que não melhoram com a operação (ELLENBOGEN, 1979). A disfagia intensa e de aparecimento precoce após cardiomiotomia está associada a falha técnica. Nas miotomias incompletas o aparecimento da disfagia ocorre na maioria dos pacientes, até seis meses após a operação (PINOTTI et al., 1979; GAYET e FEKETE, 1991). No megaesôfago avançado mesmo com realização da miotomia perfeita sob o ponto de vista técnico, o esôfago não se esvazia adequadamente por ser um órgão atônico.

É importante ressaltar que todos os pacientes deste estudo apresentavam no pré-operatório disfagia moderada ou intensa. Houve melhora 
importante da disfagia em todos os doentes. Os resultados observados com a operação de SERRA DÓRIA, em termos de alívio da disfagia são semelhantes aos obtidos com as cardiomiotomias (CECCONELLO et al., 1990; SERRA et al., 1998; PINOTTI e FELIX, 1999) e com a operação de THAL e HATAFUKU (BARBOSA et al., 1989; FERRAZ et al., 2001).

A operação de SERRA DÓRIA (1970) propiciou também melhora da regurgitação, sendo mais acentuada, na avaliação tardia. Tal fato era esperado, já que $92,4 \%$ dos pacientes estudados tinham megaesôfago grupo III e IV. A regurgitação é um sintoma que está relacionado com a estase de alimentos no esôfago; a operação propiciou diminuição da estase, tendo sido observado regressão do calibre do esôfago em vários doentes. Apesar da boa passagem pela transição esofagogástrica, seis pacientes permaneceram com o mesmo grau de dilatação esofágico, fato também relatado por ELLENBOGEN (1979), que atribuiu à fibrose e atonia a ausência de diminuição do calibre do esôfago, após cardiomiotomia. Há tendência de que o esôfago que ainda mantenha certa atividade motora, apresente bom esvaziamento com redução do calibre do esôfago, mesmo em pacientes com megaesôfago grupo IV.

Embora houvesse melhora da pirose, dois pacientes desenvolveram esofagite de refluxo no pós-operatório, apesar do emprego da gastrectomia parcial em Y-de-Roux, devido à ampla comunicação que resulta da anastomose esofagogástrica latero-lateral; os pacientes que apresentaram esofagite foram tratados clinicamente com bloqueadores $\mathrm{H} 2$ ou com inibidores de bomba de prótons, encontrando-se assintomáticos. Por outro lado, SERRA (1995) realizou nova miotomia em pacientes com recidiva dos sintomas por miotomia incompleta observou esofagite de refluxo pós-operatória em $40 \%$ dos doentes. Com a 
cardioplastia a THAL-HATAFUKU (1965) são relatados índices de esofagite de refluxo pós-operatória de 30\% (FERRAZ et al., 2001).

Vários tipos de tratamentos são sugeridos para tratamento do megaesôfago avançado, quase sempre apresentando elevados índices de complicações; na mucosectomia com conservação da túnica muscular esofágica por via cervicoabdominal com gastroplastia cervical, 27,8\% (AQUINO 1996), na esofagectomia por transsecção do diafragma, 28\% (PINOTTI e MARIANO DA ROCHA, 1999) e, na interposição de cólon, mais de 50\% (RASSI 1973).

No tratamento do megaesôfago grupo IV previamente submetidos a cardiomiotomia, CECCONELLO et al., (1990 ) não observaram óbitos em 12 pacientes submetidos a esofagectomia sem toracotomia, com gastroplastia cervical. Houve bons resultados tardios em $83,3 \%$ dos pacientes. No presente estudo a operação de SERRA DÓRIA(1970) mostrou-se, igualmente eficiente no tratamento do megaesôfago avançado. É um método mais simples do que as ressecções, podendo ser realizado em qualquer centro do interior do país, por equipes habitualmente treinadas para a realização de operações abdominais.

A principal indicação da técnica estudada é nas reoperações para megaesôfago, em que há esofagite de refluxo. Nove doentes com recidiva dos sintomas por refluxo gastroesofágico melhoraram no pós-operatório, não havendo esofagite ao estudo endoscópico, em sete. Outros autores têm também empregado a gastrectomia parcial em Y-de-Roux para tratamento de esofagite de refluxo nas reoperações para megaesôfago com excelentes resultados (FEKETE et al., 1982; GAYET e FEKETE, 1991; FEKETE e PATERSON, 1992).

O emprego de fundoplicatura em pacientes com refluxo importante decorrente de cardiomiotomia prévia, dificilmente apresenta bons resultados. 
CECCONELLO et al. (1990), observaram manutenção dos sintomas em 17/29 doentes (41.2\%) em que a fundoplicatura parcial foi associada à cardiomiotomia previamente existente. Observaram, entretanto, bons resultados em 8/9 pacientes $(88,8 \%)$, que foram submetidos a esofagectomia sem toracotomia, com gastroplastia cervical. As anastomoses esofagogástricas se acompanham, por outro lado, de esofagite de refluxo e esôfago de Barrett no coto cervical, conforme observaram CECCONELLO et al (1988), e PINOTTI et al (1991); MARIANO DA ROCHA et al., 1992; PINOTTI e MARIANO DA ROCHA(1999). A ocorrência da esofagite aumenta com os anos de seguimento pós-operatório (CECCONELLO et al., 1993; MARIANO DA ROCHA et al., 1999).

Portanto, a esofagite de refluxo representa complicação passível de ser encontrada nas reoperações de megaesôfago, com qualquer das técnicas empregadas: nova miotomia, esofagectomia com gastroplastia (esofagite do coto), cardioplastias, e mesmo na operação de Serra Dória.

Não se observou úlcera de boca anastomótica pela não realização da vagotomia associada à gastrectomia. Talvez este fato esteja relacionado à diminuição da secreção basal de ácido do estômago em pacientes com megaesôfago Chagásico (MARIANO DA ROCHA et al., 1989) e pela ressecção gástrica parcial.

Observa-se melhora do estado nutricional dos pacientes, após tratamento do megaesôfago por cardiomiotomias (ELLENBOGEN, 1979), cardioplastia (BARBOSA et al., 1981) ressecções esofágicas (CECCONELLO et al., 1988; PINOTTI et al., 1991 ) e no pós-operatório de reoperações para megaesôfago (SERRA et al., 1998). Isto se deve provavelmente à melhora da disfagia ocorrendo maior facilidade de ingestão de alimentos. A maioria dos 
pacientes deste estudo mantiveram ou ganharam peso, entretanto $35,3 \%$ perderam peso. Estes resultados podem estar relacionados à ressecção gástrica.

Não foram observados, do ponto de vista clínico, sintomas que sugerissem alteração do esvaziamento gástrico, embora estudos cintilográficos assim o demonstrem, em pacientes submetidos à gastrectomia parcial em Y-deRoux (VOGEL el. al., 1983; MATHIAS et al., 1985) para tratamento de outras afecções.

Síndrome de dumping leve ocorreu em dois (10\%) pacientes. Manifestou-se por mal estar geral durante a alimentação. Houve melhora nas primeiras semanas de pós-operatório com a introdução de medidas dietéticas. Parece não ser complicação que comprometa o resultado da operação a médio e longo prazo.

Verificou-se, assim, que a operação de SERRA DÓRIA : por ser realizada por via abdominal, podendo ser executada facilmente por cirurgiões com treinamento habitual; por apresentar baixos índices de morbimortalidade sem necessidade de cuidados intensivos no pós-operatório; por apresentar bons resultados em relação ao alívio dos sintomas, credencia-se como alternativa viável para tratamento de pacientes com megaesôfago já operado e que apresentaram recidiva dos sintomas. Há, entretanto, necessidade de novos estudos com seguimento a mais longo prazo, para se obterem conclusões mais definitivas, especialmente em relação à ocorrência de complicações mais tardias, não identificadas neste estudo. 
CONCLUSÃO 


\subsection{Conclusão}

1. A operação de Serra Dória, no tratamento cirúrgico do megaesôfago operado com recidiva dos sintomas, no presente estudo revelou baixa morbidade, sem mortalidade;

2. determinou expressivo alívio dos sintomas em especial da disfagia;

3. permite na maioria das vezes diminuição do calibre do esôfago; não houve em nenhum paciente aumento do calibre;

4. propiciou melhora da esofagite de refluxo; havendo, entretanto, a possibilidade de sua manutenção bem como do seu aparecimento em doentes que não a apresentavam. 


\section{REFERÊNCIAS BIBLIOGRÁFICAS}




\subsection{Referências Bibliográficas}

ANDREOLLO, N.A.; BRANDALISE, N.A.; LOPES, L.R.; PANTOJA, M. A Esofagectomia sem toracotomia no tratamento do megaesôfago chagásico avançado. Rev. Col. Bras. Cir., v. 15, p. 76, 1988

AQUINO, J.L.B. Tratamento do megaesôfago pela mucosectomia com conservação da túnica muscular esofágica por via cervicoabdominal. São Paulo, 1996. Tese (Doutorado) - Faculdade de Ciências Médicas, Universidade Estadual de Campinas

BARBOSA, H. BARRICHELLO, A.W.; VIANNA,A.L.; MENDELSSONH, P. Megaesôfago Chagásico: tratamento pela cardioplastia a Thal. Rev. Col. Bras. Cir., v.8, p.16-28, 1981.

BARBOSA, H.; BARRICHELLO, A.W.; VIANNA,A.L.; MENDELSSONH, P.; WATANABE, LM. Tratamento cirúrgico do megaesôfago: duas décadas de experiência numa região endêmica. Rev. Goiana Med., v.35, n. 1/4, p.123, 1989.

BOULEZ,J.; BAULIEUX,J.; MAYER,B.; PEIX, J.L.; DONNE, R.; MAILLET, P. Résultats éloignés de la myotomie de Heller dans le traitement de l'achalasie - 103 cas., Ann. Gastrol. Entéro. Hépato., v. 17, p. 321, 1981 
CECCONELLO, I.; MARIANO DA ROCHA, J.R.; POLLARA, W.M.; ZILBERSTEIN , B. Long-term evaluation of gastroplasty in achalasia. In: SIEWERT, R.; A.H. HOLSCHER, (Eds.): Diseases of the esophagus. Berlin, Springer-Verlag, 1988. p.975-979.

CECCONELLO, I.; ZILBERTEIN, B.; DOMENE, C.E.; NASI,A.; PINOTTI,H.W.; Recorrence of Symptoms after management of achalasia. In : INTERNATIONAL POLYDISCIPLINARY CONGRESS OF OESO,3ㅜ, 1990 Paris. Anais... Paris, ( s.n. ) 1990, p. 69

CECCONELLO, I.; MARIANO DA ROCHA, J.R.; ZILBERSTEIN, B.; FELIX, V.N.; PINOTTI, H.W. Reflux esophagitis and development of ectopic columnar epithelium in the esophageal stump after gastric transposition: a prospective study. In: WORLD CONGRESS OF INTERNATIONAL SOCIETY FOR DISEASES OF THE ESOPHAGUS, 5., 1993, Tokyo. Selected papers... Tokyo, Springer-Verlag, 1993.

CECCONELLO, I.; SALUM, R.A.; ZILBERSTEIN, B.; PINOTTI, H.W. When fundoplication is added to the miotomy, is there a sisk of intra-thoracic migration of the valve after reduction of the esphageal caliber? In: GIULI, R., GALMICHE, J.P, JAMIESON, G.G., SCARPIGNATO , C. (Eds.) The esophagogastric junction. John Libbey Eurotext, Paris, 1998 - p. 1441-1443 
CHAIB, S.A.; LOPASSO, F. P.; PARRA. O M.; SAAD, W. A.; VASCONCELOS, E. Tratamento do megaesôfago pela técnica de Heller-Vasconcelos . Experiencia de 200 casos. Rev. Hosp. Clin. Fac. Med. São Paulo .v.32 n.3, p.178-183, 1977

CHRISTMANN, F.E; OTTOLENGHI, C.E.; RAFFO, J.M.; GROLMAN, G.V. Técnica Quirúrgica. 11. Ed. [s.I.], El Ateneo, 1975. p. 605.

STIPA, S.; BELSEY, R. Esophagomyotomy and antireflux operation for achalasia. Chi. Gastroenterol., v. 10, p. 3, 1976

CSENDES, A.; VELASCO, N.; BRAGHETTO, I. A prospective randomized study comparingforceful dilatation and esophagomyotomy in patientswith achalásia of the esophagus. Gastroenterology, v. 80, p. 789, 1981

CSENDES, A. Results of surgical treatment of achalasia of the esophagus. Hepatogastroenterology., v.38, n.6, p.474-480, 1991.

DOR, J.; HUMBERT, P.; DOR, V.; FIGARELATT,J. L'interet de la tecnique de Nissen modifié dans la prévention du reflux aprés cardiomiotomie extramuqueuse de heller. Mem. Acad. Chir., v.88, p.877, $1962 .$.

DEL GENIO, A.; DI MARTINO, N. ; MAFETTONE , V. ; IZZO, G. ; ZAMPIELLO, P. ; MUGIONE, P. Insuccessi della terapia chirurgica dell'acalasia : diagnosi e trattamento. Ann. Ital. Chir. , LXVI , v.5, p.587-595, 1995. 
DOMENE, C.E. Cardiomiectomia com fundoplicatura parcial videolaparoscópica no tratamento do megaesôfago não avançado sistematização técnica e avaliação clínica e funcional. São Paulo, 1996. Tese (Livre Docência) - Faculdade de Medicina, Universidade São Paulo.

ELLENBOGEM, G. Megaesôfago não avançado tratamento pela cardiomiotomia associada à esofagofundogastropexia . Avaliação clínica , morfológica e funcional dos seus resultados . São Paulo, 1979.Tese( Livre Docência ) - Faculdade de Medicina, Universidade de São Paulo.

ELLIS, Jr ,F.H.; GIBB, S.P. Reoperation after esophagomyotomy for acalasia of the esophagus. Am. J. Surg., v.129, p.407, 1975.

ELLIS Jr., F.H.; CROZIER, R.E.; GIBB, S.P. Reoperative achalasia surgery . J. Thorac. Cardiovasc. Surg., v.92, p.859-865, 1986.

FERREIRA-SANTOS, R. Tratamento cirúrgico da aperistalse esofágica (Megaesôfago). Ribeirão Preto, 1963. Tese (Provimento de Cátedra) Faculdade de Medicina de Ribeirão Preto, Universidade de São Paulo.

FEKETE, F.; LORTAT-JACOB, J.L. Échecs et prétendus échecs de lópération de Heller pour méga-oesophage idiopathique. Étude de 55 malades réopérés. Ann. Chir., v. 31, n.6, p. 515-524. 1977 
FEKETE, F.; BREIL, P.H.; TOSSEN, J.C. Reoperation after Heller's operation for achalasia and other motility disorders of the esophagus: a studyof eight-one reoperation. Int. Surg., v.67, p.103-110, 1982.

FEKETE, F.; BREIL, P.H. Les réintervencion aprés intervention de Heller pour achalasie ey autres dysfonctionnements moteurs de l'oesophage. Acta Chir. Belgica, v.82, p.333-343, 1982b.

FEKETE, F.; PATERON, D. What is the place of antrectomy with Roux-en-Y in the treatementof reflux desease? Experience With 83 total duodenal diversions. World. J. Surg. v. 16, p. 349-353, 1992

FELIX,V.N. Tratamento do megaesôfago chagásico incipiente. Estudo comparativo entre a dilatação hidrostática forçada da cárdia e esofagocardiomiotomia com esofagogastrofundopexia. São Paulo, 1994 Tese (Livre Docência ) - Faculdade de Medicina da Universidade de São Paulo

FELIX, V.N.; CECCONELLO, I.; PINOTTI, H.W. Diagnóstico da causa de recidiva após tratamento cirúrgico do megaesôfago não avançado. Arq. Bras. Cir. Dig. (ABCD), v.5, p.259-61, 1989. Supl. 4.

FAROOQ, P. A.; KEREN, D.F. Barrett's esophagus complicating achalasia after esophagomyotomy. J. Clin. Gastroenterol. V. 9, n. 2, p. 232-237, 1987 
FERRAZ, A.A.B.; NÓBREGA Jr, B.G.; MATHIAS, C.A.; BACELAR, T. S.; LIMA, F.E.A.; FERRAZ, E.M. Late results on the surgical tretment of chagasic megaesophagus with the Thal-Hatafuku procedure. J. Am. Coll. Surg., v.193, p.493-498, 2001.

GRONDAHL, N.B. Apud CHISTIMANN-OTOLENGHI. 1975

GAYET, B.; FEKETE, F. Surgical managemente of failed esophagomyotomy (Heller operation). Hepatogastroenterology., v.38, p.488-92, 1991.

GOLDEMBERG, S. Cirurgia megaesôfago - operação de Grondahl-Dória modificada. Rev. Goiana Med., v.19, p195-201,1973

GOTTSTEIN, G.Technik und klinik der oesophagus kopie. Mitt Grenzgeb Med. Chiv. V. 8, p. 57, 1991 (apud Ellenbogem 1979)

GROENVELDT,F.R. de B.Over cardiospasmus. Ned. Gencesk v. 62, p. 1281, 1918 (apud Ellenbogem 1979)

HELLER, E. Extramukose cardiaplastik beim chonischen cardiospasmus mit dilatation des oesophagus. Mitt. Grenzgeb. Med. Chir., v. 27, p. 141-149, 1913 (apud Ellenbogem , 1979) 
HEYROVSKY,H. Casuistik und therapie der idiopatischen dilatation der speiseoher. Oesophagogastroanastomosis., Langnbeecks Arch. Klin.Chir. v. 100, p. 703-715,1913 (apud Ellenbogem 1979)

HOLT, C.J.; LARGE, A.M. Surgical management of reflux esoghagitis. Ann. Surg., v.153, p.555, 1961.

HERBELLA , F.A.M.; DEL GRANDE,J.C.; LOURENÇO,L.G.; MANSUR, N.S.; HADDAD,M.C. Resultados tardios da operação de HELLER associado à fundoplicatura no tratamento do megaesôfago: análise de 83 casos. Rev. Assoc. Med. Bras., v. 45, n. 4, p. 317-322, 1999

HERRINGTON, J.L.; SAWYERS,J.L. Remedial operations, In. Nyhus L.M., Waltell, c. (Eds). Surgery of the stomach and duodenum. Boston, Little Brow, e Co, 1977 , p.537-566,

JAMIESON, G.G. Gastro-esophageal reflux following myotomy for achalasia. Hepato-Gastroenterol.., v.38, p. 506-509, 1991

JEKLER, J.; LHOTKA, J. Modified heller procedure to prevent postoperative reflux esophagitis in patients with achalasia. Am. J. Surg., v.113, n.2, p.251-4, 1967. 
LORTAT-JACOB, J.L.; BINET,J.P.; MAILLARD,J.N. . La prévention des hemorragies digestivesarpés operation de Heller. Ass. Franc. Chi. v.58, p.162, 1956.

LUQUETTI, A.O. Chagas disease and national social security the main cause of incapacity for work among infectious and parasitic diseases in Goiás state. In: CONGRESSO DA SOCIEDADE BRASILEIRA DE MEDICINA TROPICAL, 31., 1996, Goiânia. Anais... Goiânia, [s.I.], 1996.

MATHIAS, J. R.; FERNANDEZ, A.; SNINSKY, C.A.; CLENCH, M.H.; DAVIS, R.H. Nausea, vomiting, and abdominal pain after Roux-en-Yanastomosis: Motility of the jejunal limb. Gastroenterology, v.88, p.101-107, 1985

MENGUY, R. Surgical pos and cons. Surg. Gynecol.Obstet., v. 147 p. 237, 1978

MERCER,C.D.; HILL, L.D. Reopaeration after failed esophagomyotomy for achalasia. Can.J. Surg. v. 29, n.3, p. 177-180, 1986

MERENDINO, K.A.; DILLARD, D.K. The concept of sphincter substitution by an interposed jejunal segment for anatomic and physiologic abnormalities at the esophagogastric junction, with special reference to reflux esophagitis, cardiospasm and esophageal varices. Ann. Surg., v.142, p.486-509, 1955. 
MARIANO DA ROCHA, J.R.; CECCONELLO, I.; ZILBERSTEIN, B.; SALLUM, R.A.A.; SAKAI, P.; ISHIOCA,S.; PINOTTI,H.W. Esôfago de Barrett no coto esofagiano após esofagectomia subtotal com esofagogastroplastia cervical Rev. Hosp. Clín. Fac. Med. S. Paulo, v. 47, n. 2, p. 69-70, 1992

MARIANO DA ROCHA, J.R.; SALLUM , R.A.A.; OLIVEIRA, M.A.; Complicações imediatas e tardias da esofagectomia por transecção mediana do diafragma com esofagogastroplastia, para tratamento do megaesofago avançado. In: Complicações em operações do aparelho digestivo, São Paulo, Fungastro,1999

MENDELSSONH, P.; VIANNA,A.L.; BARICHELLO, A.W.; WATANABE,L.M.; BARBOSA, H. Megaesôfago chagásico recidivado: Tratamento pela cardioplastia à Thal. Rev. Goiana Med., v. 30, p. 97-109, 1984

ORRINGER, M.B.; STIRLING, M.C. Esophageal resection for achalasia: Indications and results. Ann. Thorac. Surg., v. 47 p.340-345, 1989

PATRICK,D.L.; PAYNE,W.S.; OLSEN, A.M.; ELLIS, F.H. Reoperation for achalasia of the esophagus. Arch. Surg., v. 103, n. 2, p. 122-128, 1971

PATTI, M.G.; PELLEGRINI, C.A.; ARCERITO, M.; TONG, J.; MULVIHILL, S.J.; WAY, L.W. Comparison of medical and minimally invasive surgical therapy for primary esophageal motility disorders. Arch. Surg. v. 130, p. 606-616, 1995 
PERACCHIA, A.; NOSADINA,A.; TREMOLADA, C.; BARDINI, R. Reoperation after Heller's operation for megaesophagus. Chirurgie, v. 112 n. 1, p. 50-55, 1986

PINOTTI, H.W.; GAMA RODRIGUES, J.J.; ELLENBOGEN, G.; RAIA, A. Nova técnica no tratamento cirurgico do megaesofago: esofagocardiomiotomia associada com esofagofundogastropexia. Rev. Goiana Med., v.20, n. 1 / 2, p.1-13, 1974.

PINOTTI, H. W. Acesso extrapleural ao esôfago por frenolaparotomia. Rev. Assoc. Med. Bras., v.22, p.57-60, 1976.

PINOTTI, H.W. Esofagectomia subtotal por túnel transmediastinal sem toracotomia. Rev. Assoc. Med. Bras. V. 23, n.11, p. 395-398, 1977

PINOTTI, H.W.; FELIX, V.N.; DOMENE, C.E.; PURCELI, E.L. Recurrence of disphagia in patientes operated on for megaesophagus: analysis of determining factors . Chir. Gastroenterol., v. 13 p.1-7, 1979

PINOTTI, H.W.; ZILBERTEIN, B.; POLARRA, W.; RAIA, A.A. Esophagectomy without thoracotomy. Surg. Gynecol. Obstet., v. 152, p. 345-346, 1991 
PINOTTI, H.W.; CECCONELLO, I.; MARIANO DA ROCHA , J.R.; ZILBERTEIN, B. Ressection for achalasia of the esophagus. Hepatogastroenterology, v.38, p.470-473, 1991.

PINOTTI , H.W.; FELIX, V.N.; ZILBERSTEIN, B. CECCONELLO, I. Surgical complications of Chagas diseases: megaesophagus, achalasia of the pylorus, and cholelithiasis. World J. Surg., v.15, p.198-204, 1991 b.

PINOTTI, H.W.; FELIX, W.N. Reoperação no megaesôfago recidivado por transecção mediana do diafragma. In: PINOTTI, H.W. Acesso ao esôfago torácico por transecção mediana do diafragma. São Paulo, Atheneu, 1999 , p. $121-128$

PINOTTI, H.W.;MARIANO DA ROCHA, J.R. Acesso por transecção mediana do diafragma do esôfago no tratamento do megaesôfago avançado - Resultados imediatos In: PINOTTI, H.W. Acesso ao esôfago torácico por transecção mediana do diafragma. São Paulo, Atheneu, 1999, p. 167-172

POWELL, D.C.; BIVINS, B.A.; BELL, R.M.; GRIFFEN, Jr W. O. Techinical complications of Roux-en-Y gastrojejunostomy Arch. Surg., v. 118, p. 922925,1983

RASSI, L. Esofagocoloplastia retroesternal no tratamento cirúrgico do dolicomegaesôfago. Rev. Goiana Med., v.19, p.153-168, 1973. 
REZENDE, J.M.; LAUAR, K.M.; OLIVEIRA, A.R. Aspectos clínicos e radiológicos da aperistalse do esôfago. Rev. Bras. Gastroenterol., v.12, p.247, 1960.

ROUX, P.P.E. Chirugie gastrointestinale. Rev. Chi., v. 13, p. 402-413, 1893 . (apud POWELL, et al.,1983)

SERRA DÓRIA, O.B.; Silva Dória , O. M.; SILVA DÓRIA, O R. Nova conduta cirúrgica para o tratamento do megaesôfago (Técnica de Serra Dória) Anais Paulista de Medicina e Cirurgia ., v.97, n. 2, p.115-121, 1970.

SERRA DÓRIA, O.B.; Silva Dória , O. M.; SILVA DÓRIA, O R. Operação de Serra Dória para o tratamento do megaesôfago . Considerações quanto a originalidade do método Anais Paulista de Medicina e Cirurgia ., v.99, n. 2, p.112-119, 1972.

SERRA DÓRIA, O.B. Tratamento cirúrgico do megaesôfago operação de Serra Dória. Rev. Goiana Med., v.19, p.185-193, 1973.

SERRA, H.O. Reoperação nos casos de miotomia incompleta. São Paulo, 1995. Dissertação (Mestrado) - Faculdade de Medicina, Universidade São Paulo.

SERRA, H.O.; FELIX, V.N.; CECCONELLO, I.; PINOTTI, H.W. Manometric aspects of the incomplete myotomy. Arq. Bras. Cir. Dig., v.11, n.3/4, p.62$65,1996$. 
SERRA, H.O.; FELIX, V.N.; CECONNELLO , I.; PINOTTI, H.W. Reaplication of myotomy and fundoplication in the surgical treatment of recurrent dysphagia after incomplete myotomy. Rev. Hosp. Clin. Fac. Med. São Paulo, v.53, n.3, p.129-133, 1998.

THAL, P. A HATAFUKU, T.; KURTZMAN, R. New operation for distal esophageal stricture. Arch. Surg., v.90, p.464, 1965.

VOGEL,B.S.; VAIR,D.B.; WOODWARD,M.D. Alteration in gastrointestinal emptying of $99 \mathrm{~m}$-Technetium- labeled solids following sequential antrectomy, truncal vagotomy and Roux-Y gastroenterostomy Ann. Surg., v. 198,n, 4, p.506-513, 1983

WANDERLEY, D.M.V. Epidemiologia da doença de chagas. Rev. Soc. Cardiol. São Paulo, v.4, n.2, mar./april, p.77-83, 1994.

WOLFER, A. Gastro-enterostomic. Zentralbl. Chi., v.8 p. 705-713, 1881 (apud POWELL et al., 1983)

ZAAIJER,J.H. Cardiospasm in the aged. Ann. Surg. v.77, p. 615, 1923.( apud ELENBOGEM , 1979) 
ANEXOS 


\section{Causas de recidiva}

\begin{tabular}{lccccc}
\hline \multicolumn{2}{c}{ Pacientes } & Endoscopia & $\begin{array}{c}\text { Rx } \\
\text { (grupo megaesôfago) }\end{array}$ & $\begin{array}{c}\text { Tempo recidiva } \\
\text { sintomas }\end{array}$ & Causa Recidiva \\
\hline 01 & DMS & Esofagite & II & Sem melhora & Esofagite \\
02 & JAP & Esofagite & III & 1 ano & Esofagite \\
03 & LAO & Esofagite & III & 6 meses & Esofagite \\
04 & ARS & Esofagite & IV & Sem melhora & Esofagite \\
05 & LCN & Normal & IV & Sem melhora & Má indicação \\
06 & ARF & Normal & IV & 2 meses & Má indicação \\
07 & VJS & Esofagite & III & 2 anos & Esofagite \\
08 & TLR & Estenose & III & 1 ano & Fibrose \\
09 & JCC & Normal & IV & 2 meses & Má indicação \\
10 & AAS & Normal & III & Sem melhora & Miotomia \\
11 & MCS & Normal & III & 4 anos & incompleta \\
12 & OCC & Esofagite & III & 4 meses & Fsofose \\
13 & RAG & Esofagite & III & 2 anos & Esofagite \\
14 & JRDC & Normal & III & 1 ano & Fibrose \\
15 & MBS & Normal & III & 2 anos & Fibrose \\
16 & BPS & Esofagite & IV & 14 anos & Esofagite \\
17 & SBS & Normal & IV & 6 anos & Má indicação \\
18 & JNS & Esofagite & IV & 1 ano & Esofagite \\
19 & JRS & Normal & IV & Sem melhora & Má indicação \\
20 & AAS & Normal & III & 4 anos & Fibrose \\
\hline
\end{tabular}


Anexo 2

\section{Avaliação clínica}

\begin{tabular}{|c|c|c|c|c|c|c|c|c|c|c|c|}
\hline \multirow{3}{*}{ Pacientes } & \multicolumn{3}{|c|}{ Disfagia } & \multicolumn{3}{|c|}{ Pirose } & \multicolumn{3}{|c|}{ Regurgitação } & \multicolumn{2}{|c|}{ Peso ( Kg) } \\
\hline & \multirow[t]{2}{*}{ Pré-op } & \multicolumn{2}{|c|}{ Pós-op } & \multirow[t]{2}{*}{ Pré-op } & \multicolumn{2}{|c|}{ Pós-op } & \multirow[t]{2}{*}{ Pré-op } & \multicolumn{2}{|c|}{ Pós-op } & \multirow[t]{2}{*}{ Pré-op } & \multirow[t]{2}{*}{ Pós-op } \\
\hline & & ime & tar & & ime & tar & & ime & tar & & \\
\hline 01 DMS & $\mathrm{I}$ & $\mathrm{L}$ & $\mathrm{M}$ & $\mathrm{P}$ & $A$ & $A$ & A & $A$ & $A$ & 45 & 46 \\
\hline 02 JAP & I & $A$ & $A$ & $\mathrm{P}$ & $A$ & $A$ & $\mathrm{P}$ & $A$ & $A$ & 55 & 59 \\
\hline 03 LAO & $\mathrm{M}$ & A & $\mathrm{L}$ & $P$ & A & A & $P$ & A & $\mathrm{P}$ & 63 & 50 \\
\hline 04 ARS & I & $A$ & $A$ & $P$ & $A$ & $A$ & $P$ & $A$ & $A$ & 30 & 47 \\
\hline $05 \mathrm{LCN}$ & I & A & - & $P$ & A & - & $\mathrm{P}$ & A & - & - & - \\
\hline $06 \quad$ ARF & $\mathrm{I}$ & $A$ & $\mathrm{~L}$ & A & $A$ & $A$ & $\mathrm{P}$ & $A$ & $A$ & 68 & 67 \\
\hline 07 VJS & $\mathrm{I}$ & $A$ & $A$ & $P$ & $A$ & $A$ & $P$ & $A$ & $A$ & 69 & 65 \\
\hline 08 TLR & I & $A$ & $A$ & A & $P$ & A & $P$ & $P$ & A & 50 & 41 \\
\hline $09 \mathrm{JCC}$ & $\mathrm{I}$ & $A$ & $A$ & A & $A$ & $A$ & $P$ & $A$ & $A$ & 44 & 49 \\
\hline 10 AAS & $\mathrm{I}$ & $A$ & $\mathrm{~L}$ & $\mathrm{P}$ & A & $P$ & A & $A$ & $A$ & 50 & 50 \\
\hline 11 MCS & I & A & $A$ & $P$ & $A$ & A & $P$ & $A$ & $A$ & 47 & 69 \\
\hline 12 OCC & I & A & - & $\mathrm{P}$ & A & - & $\mathrm{P}$ & A & - & 44 & - \\
\hline 13 RAG & I & $A$ & $A$ & $\mathrm{P}$ & $A$ & $\mathrm{P}$ & $\mathrm{P}$ & $A$ & $A$ & 47 & 46 \\
\hline 14 JRDC & $\mathrm{I}$ & $\mathrm{L}$ & $A$ & $\mathrm{P}$ & $A$ & $A$ & $P$ & $P$ & $A$ & 53 & 63 \\
\hline $15 \mathrm{MBS}$ & I & $A$ & $\mathrm{~L}$ & $A$ & $A$ & $P$ & $\bar{A}$ & $A$ & $A$ & 41 & 41 \\
\hline 16 BPS & I & $\mathrm{L}$ & $\mathrm{L}$ & $A$ & $A$ & $A$ & $P$ & $\mathrm{P}$ & $P$ & 63 & 53 \\
\hline 17 SBS & $M$ & $\mathrm{~L}$ & $\mathrm{~L}$ & A & $\mathrm{P}$ & A & $P$ & $\mathrm{P}$ & A & 83 & 78 \\
\hline 18 JNS & $M$ & $A$ & $A$ & $P$ & $A$ & $A$ & $P$ & $A$ & $A$ & 69 & 64 \\
\hline 19 JRS & I & $A$ & $A$ & A & $A$ & $A$ & $P$ & $A$ & $A$ & 46 & 46 \\
\hline 20 AAS & I & A & - & $P$ & $A$ & - & $\mathrm{P}$ & A & - & 42 & - \\
\hline
\end{tabular}
$A=$ Ausente
$\mathrm{P}=$ Presente
$\mathrm{I}=$ Intenso
$\mathrm{M}=$ Moderado
$\mathrm{L}=$ Leve
- = Sem informação

ime = imediato

tar = Tardio 
Anexo 3

\section{Avaliação Radiológica e endoscópica}

\begin{tabular}{lccccc}
\hline \multirow{2}{*}{ Pacientes } & \multicolumn{2}{c}{ Endoscopia } & \multicolumn{2}{c}{ Rx } \\
& & Prupo megaesôfago) \\
\cline { 3 - 6 } & & Psofop & Pós-op & Pré-op & Pós-op \\
\hline 01 & DMS & Esofagite & Sem esofagite & II & II \\
02 & JAP & Esofagite & Esofagite & III & II \\
03 & LAO & Esofagite & Sem Esofagite & III & II \\
04 & ARS & Esofagite & Sem esofagite & IV & - \\
05 & LCN & Sem esofagite & - & IV & IV \\
06 & ARF & Sem esofagite & Sem esofagite & IV & IV \\
07 & VJS & Esofagite & Sem esofagite & III & II \\
08 & TLR & Estenose & Sem esofagite & III & - \\
09 & JCC & Sem esofagite & Esofagite & IV & III \\
10 & AAS & Sem esofagite & Esofagite & III & II \\
11 & MCS & Sem esofagite & Sem esofagite & III & III \\
12 & OCC & Esofagite & - & III & - \\
13 & RAG & Esofagite & Esofagite & III & - \\
14 & JRDC & Sem esofagite & Sem esofagite & III & - \\
15 & MBS & Sem esofagite & Sem esofagite & III & III \\
16 & BPS & Esofagite & Sem esofagite & IV & - \\
17 & SBS & Sem esofagite & Sem esofagite & IV & III \\
18 & JNS & Esofagite & Esofagite & IV & IV \\
19 & JRS & Sem esofagite & Sem esofagite & IV & II \\
20 & AAS & Sem esofagite & - & III & - \\
\hline
\end{tabular}


Anexo 4

Tempo de internação, cirurgia, segmento e complicações pósoperatórias

\begin{tabular}{|c|c|c|c|c|c|}
\hline \multicolumn{2}{|c|}{ Pacientes } & \multirow{2}{*}{$\begin{array}{c}\begin{array}{c}\text { Tempo } \\
\text { internação } \\
\text { (dias) }\end{array} \\
8\end{array}$} & \multirow{2}{*}{$\begin{array}{c}\begin{array}{c}\text { Tempo de } \\
\text { Cirurgia } \\
\text { (minutos) }\end{array} \\
240\end{array}$} & \multirow{2}{*}{$\begin{array}{c}\text { Tempo Seguimento } \\
\text { ( meses) }\end{array}$} & \multirow{2}{*}{$\begin{array}{c}\text { Complicações } \\
-\end{array}$} \\
\hline 01 & DMS & & & & \\
\hline 02 & JAP & 9 & 155 & 12 & - \\
\hline 03 & LAO & 10 & 240 & 12 & - \\
\hline 04 & ARS & 8 & 190 & 108 & anemia \\
\hline 05 & $\mathrm{LCN}$ & 22 & 180 & 2 & fístula \\
\hline 06 & ARF & 9 & 160 & 8 & - \\
\hline 07 & VJS & 10 & 290 & 42 & - \\
\hline 08 & TLR & 10 & 170 & 12 & - \\
\hline 09 & $\mathrm{JCC}$ & 10 & 405 & 14 & pneumotorax \\
\hline 10 & AAS & 9 & 385 & 16 & - \\
\hline 11 & MCS & 9 & 365 & 24 & fístula \\
\hline 12 & occ & 42 & 265 & 2 & - \\
\hline 13 & RAG & 13 & 255 & 96 & - \\
\hline 14 & JRDC & 14 & 285 & 30 & dumping leve \\
\hline 15 & MBS & 10 & 215 & 12 & - \\
\hline 16 & BPS & 16 & 405 & 11 & - \\
\hline 17 & SBS & 10 & 265 & 12 & - \\
\hline 18 & JNS & 9 & 150 & 6 & - \\
\hline 19 & JRS & 10 & 140 & 8 & dumpig leve \\
\hline 20 & AAS & 9 & 165 & 4 & - \\
\hline
\end{tabular}

